\title{
Predictors of Verb-Mediated Anticipatory Eye Movements in the Visual World
}

\author{
Florian Hintz \\ Radboud University
}

\author{
Antje S. Meyer and Falk Huettig \\ Max Planck Institute for Psycholinguistics, Nijmegen, the \\ Netherlands, and Radboud University
}

\begin{abstract}
Many studies have demonstrated that listeners use information extracted from verbs to guide anticipatory eye movements to objects in the visual context that satisfy the selection restrictions of the verb. An important question is what underlies such verb-mediated anticipatory eye gaze. Based on empirical and theoretical suggestions, we investigated the influence of 5 potential predictors of this behavior: functional associations and general associations between verb and target object, as well as the listeners' production fluency, receptive vocabulary knowledge, and nonverbal intelligence. In 3 eye-tracking experiments, participants looked at sets of 4 objects and listened to sentences where the final word was predictable or not predictable (e.g., "The man peels/draws an apple"). On predictable trials only the target object, but not the distractors, were functionally and associatively related to the verb. In Experiments 1 and 2, objects were presented before the verb was heard. In Experiment 3, participants were given a short preview of the display after the verb was heard. Functional associations and receptive vocabulary were found to be important predictors of verb-mediated anticipatory eye gaze independent of the amount of contextual visual input. General word associations did not and nonverbal intelligence was only a very weak predictor of anticipatory eye movements. Participants' production fluency correlated positively with the likelihood of anticipatory eye movements when participants were given the long but not the short visual display preview. These findings fit best with a pluralistic approach to predictive language processing in which multiple mechanisms, mediating factors, and situational context dynamically interact.
\end{abstract}

Keywords: anticipatory eye movements, associations, predictive language processing, production-based prediction, receptive vocabulary

Human communication is fast and efficient. This may at least partly be attributable to the fact that we can often predict words that are likely to come up next. Indeed, an impressive amount of experimental evidence has accumulated suggesting that readers and listeners can predict linguistic and nonlinguistic information (e.g., Altmann \& Kamide, 1999; Arai \& Keller, 2013; Chen, Gibson, \& Wolf, 2005; DeLong, Urbach, \& Kutas, 2005; Federmeier, McLennan, De Ochoa, \& Kutas, 2002; Laszlo, Stites, \& Federmeier, 2012; Rommers, Meyer, Praamstra, \& Huettig, 2013; Staub \& Clifton, 2006; Van Berkum, Brown, Kooijman, Zwitserlood, \& Hagoort, 2005; Wicha, Moreno, \& Kutas, 2003, 2004; and many others).

Spoken language is often used with reference to the visual environment of the language users. Many studies investigating prediction therefore have used the visual world paradigm,

This article was published Online First March 13, 2017.

Florian Hintz, Centre for Language Studies, Radboud University; Antje S. Meyer and Falk Huettig, Max Planck Institute for Psycholinguistics, Nijmegen, the Netherlands, and Donders Institute for Brain, Cognition, and Behavior, Radboud University.

We thank Annelies van Wijngaarden as well as Sophie Kirkels and Marloes Wensink for assistance in preparing and running the experiments as well as Joost Rommers and Suzanne Jongman for useful discussions.

Correspondence concerning this article should be addressed to Florian Hintz, who is now at Max Planck Institute for Psycholinguistics, P.O. Box 310, 6500 AH Nijmegen, the Netherlands. E-mail: florian.hintz@mpi.nl where participants integrate spoken linguistic input with copresent visual referents (see Huettig, Rommers, \& Meyer, 2011, for a review). A seminal study was conducted by Altmann and Kamide (1999). They presented listeners with semirealistic scenes and spoken sentences, which referred to the visual scenes. For instance, participants saw a scene depicting a boy, a cake, and some toys while hearing the sentence "The boy will move the cake" or "The boy will eat the cake." Altmann and Kamide observed that eye movements were directed to the cake, which was the only edible object in the scene, significantly earlier when the verb was "eat" than when it was "move." They interpreted these findings as evidence that information conveyed by a verb can be used to anticipate an upcoming theme. Many later studies have confirmed this conclusion. For instance, Mani and Huettig (2012) found that even 2-year-olds predict upcoming words that fit thematically with familiar verbs.

Although a number of theoretical proposals have been put forward (e.g., Altmann \& Mirković, 2009; Dell \& Chang, 2013; Federmeier, 2007; Huettig, 2015; Kamide, 2008; Kutas, DeLong, \& Smith, 2011; Pickering \& Garrod, 2007, 2013), we still know surprisingly little about the mechanisms and mediating factors that underlie such verb-mediated anticipatory eye gaze. However, this is an important question because the idea that prediction is a fundamental principle of human information processing has gained considerable ground over recent years (e.g., Clark, 2013; Friston, 2010). 
The current work is based on the hypothesis that prediction is not a unitary process, but rather engages a number of mechanisms in a flexible and context-dependent manner (cf. Huettig, 2015; Mani \& Huettig, 2013). Specifically, we assume that anticipatory language processing is influenced both by properties of the incoming linguistic stimulus and by properties inherent to the listeners. We focused on verb-mediated predictions and investigated the influence of five potential predictors of anticipatory eye gaze behavior: functional associations between verb and noun, general word associations between verb and noun, production fluency, receptive vocabulary knowledge, and nonverbal intelligence. Dutch participants took part in a visual world eye-tracking experiment. They heard predictable and nonpredictable sentences (e.g., "The man peels/draws an apple") while looking at sets of four objects, one of which was referred to in the spoken sentence. In Experiments 1 and 2, participants were given ample time to preview the objects prior to the critical spoken verb. In Experiment 3, the preview period was greatly reduced. Based on the previous literature, we predicted that in predictable sentences, participants would anticipate the target object (e.g., apple) before it was mentioned in the sentence. The key question was to which extent the associations and listener variables would affect anticipatory eye movements. In the remainder of this introduction, we motivate the choices of the predictor variables.

\section{Functional Associations}

The relationship between a verb and the nouns it typically co-occurs with has previously been discussed to exert a substantial influence on sentence processing (Ferretti et al., 2001; cf. Moss et al., 1995). In linguistic work such relationships are often termed selectional restrictions (Chomsky, 2014; Katz \& Fodor, 1963) or thematic roles (Dowty, 1991; Gruber, 1965; Jackendoff, 1987), defining the types and nature of arguments a verb could take. McRae and colleagues (Ferretti, McRae, \& Hatherell, 2001; McRae, Ferretti, \& Amyote, 1997) developed rating paradigms to quantify such thematic role relationships (asking participants to answer questions such as "How common is it for an apple to be peeled?") and showed that animacy decision times were shorter for nouns that were primed by typical transitive verbs as compared with unrelated verbs. Relatedly, Moss and colleagues (Moss, Ostrin, Tyler, \& MarslenWilson, 1995; Moss, McCormick, \& Tyler, 1997) used priming methods to examine how listeners access different types of semantic information, including functional knowledge (see Neely, 1991, for extensive review). They found that lexical decision times were shorter for nouns that were preceded by functionally related nouns (e.g., hammer-nail; theater-play) compared with unrelated nouns, which led them to conclude that functional knowledge is a particularly salient aspect of word meaning. Against this background, it is conceivable that functional verb-noun relationships have a strong influence on verb-mediated anticipatory eye gaze. In the present work we refer to such verb-noun relationships as 'functional associations,' rather than using the largely synonymous terms selectional restrictions or thematic roles, to highlight that a particular type of relationship - the typical function of the object in the action context implied by the verb-is at stake.
Consistent with such a proposal, a visual world eye-tracking study by Kukona, Fang, Aicher, Chen, and Magnuson (2011) suggested that functional verb-noun associations influence verb-mediated anticipatory eye gaze even if they conflict with the event established by the sentential context. Participants listened to spoken sentences such as "Toby arrests the crook" while looking at displays showing pictures of five characters. Two of those characters were not related to the event described in the sentence. On all trials, a picture of Toby (a neutral character introduced prior to the experiment) was shown in the center of the screen. Toby served as the agent in all sentences. Crucially, the remaining two pictures featured agent and patient characters who were likely participants in the event described in the sentence (e.g., a crook and a policeman). Interestingly, after having heard "Toby arrests," participants made eye movements to both the picture of the crook and the picture of the policeman despite the fact that the spoken sentence had already unfolded beyond the subject/agent position and the agent role was taken up by Toby. Although looks to the crook and looks to the policeman differed in magnitude (the picture of the policeman was, however, fixated more than the pictures of the unrelated characters), the results suggest that upon processing a transitive verb such as 'arrest,' functionally associated concepts were preactivated, irrespective of their thematic fit with the local sentence context.

Further support for a role of functional associations in anticipatory language processing comes from a study by Borovsky, Sweeney, Elman, and Fernald (2014), who tested how children between three and 10 years of age and adults employed recently learned connections between agents, actions, and objects to anticipate upcoming words. They showed that adults and school-age children learned the agent-action-object relationships and activate this knowledge in subsequent language processing. Importantly and in contrast to the older children and the adults, 3- to 4-year-old children's anticipatory fixations indicated a processing strategy based on longer-term associations and a failure to integrate new combinatorial information within the sentence. The authors argued that agent-action-object associations exerted a substantial influence on anticipatory language processing early on in development. As they proposed, the influence of these associations may be down-weighted over the course of development in favor of combinatorial information.

In the present study we examined whether functional associations predicted verb-mediated anticipatory eye gaze in adults. To assess the strength of functional associations, we employed a rating task developed by Ferretti and colleagues (2001) where the participants are asked to indicate how likely a particular noun is to undergo the action implied by the verb at hand (e.g., How common is it for an apple to be peeled?).

\section{General Word Associations}

Functional associative knowledge is not the only type of associative knowledge that connects verbs and nouns. Another possibility is that more 'general word associations' (sometimes termed contingent probabilities, Amato \& MacDonald, 2010; Gennari \& MacDonald, 2009) underlie verb-based anticipatory eye move- 
ments. ${ }^{1}$ General word associations are typically operationalized using free word association tasks where participants process an auditory or visual cue word and are asked to say or write down one or more words, which come to their minds on processing that cue (e.g., De Deyne, Navarro, \& Storms, 2013; Nelson, McEvoy, \& Schreiber, 2004). General word associations may include or be influenced by functional associations (e.g., on processing the verb 'peel' peelable objects may be retrieved such as apples, bananas and/or oranges). However, it is typically assumed that free word association tasks are sensitive to a number of different types of associations (e.g., semantic, phonological, orthographic, visual, etc., cf. Shelton \& Martin, 1992). For example, participants in free word association tasks often retrieve words that are phonologically associated with the cues (e.g., saying "heel" given the cue "peel").

How likely are general word associations to influence verbmediated anticipatory eye gaze? Several visual world studies have investigated the effects of (noun-noun) semantic relationships on listeners' language-mediated eye gaze. Yee and Sedivy (2006) presented participants with visual displays that included semantically related pairs of objects (e.g., lock and key) and unrelated objects. On hearing the word "key" participants fixated the picture of the semantic competitor lock reliably more than the semantically unrelated distractors in the scene. As lock and key are strongly associatively related according to free word association tasks, the results suggest that associative relationships mediated eye gaze in this study. Moreover, Duñabeitia, Aviles, Afonso, Scheepers, and Carreiras (2009) found that associative relationships predicted eye gaze in a similar visual world study. Their participants however tended to fixate more and earlier on depicted objects that were (free) associates of abstract words than (free) associates of concrete words. This result suggests that associated concepts are more readily retrieved for abstract than for concrete words. To give a final example, Iordanescu, Grabowecky, and Suzuki (2011; see also Iordanescu, Guzman-Martinez, Grabowecky, \& Suzuki, 2008) reported evidence for facilitating effects of sound-vision mappings in a visual search task: Hearing the characteristic sound "meow" resulted in faster location of the picture of the associated animal cat, as compared with an unassociated sound. This result is consistent with the notion that simple (nonfunctional) associations may influence language-mediated eye gaze.

It is worth mentioning that Huettig and Altmann (2005; see also Huettig, Quinlan, McDonald, \& Altmann, 2006, for similar results) demonstrated that eye gaze can also be directed immediately, as a word unfolds, toward conceptually related but nonassociated objects. This suggests that looks to a lock on hearing "key" are not solely driven by associative relationships.

In short, there is some support for the view that word-object mapping in the visual world paradigm is influenced by general associative relationships. However, the influence of such associations in verb-mediated predictions remains to be established. We examined the extent to which general word associations predict verb-mediated anticipatory eye movements in the visual world paradigm. General verb-noun association strength was assessed using a continuous free verb-noun association task where participants are asked to write down the first three nouns that come to mind when reading a given verb.

\section{Production Fluency}

Another possibility that is frequently raised is that predictive language processing may be supported by language production mechanisms. According to this proposal, the language production system is covertly used to anticipate upcoming language input during comprehension (Chang, Dell, \& Bock, 2006; Dell \& Chang, 2013; Hintz, Meyer, \& Huettig, 2016; Pickering \& Garrod, 2007, 2013; Schiller, Horemans, Ganushchak, \& Koester, 2009).

Chang, Dell, and Bock's (2006; see also Dell \& Chang, 2013) dual path model is an explicit implementation of such a production-based prediction account. The authors claim that predicting the next word is akin to producing the next word during sentence production. Moreover, they argue that prediction is central to language acquisition. A core component of their model is an error-based learning mechanism. Learning occurs when the model's production-based predictions are compared against utterances by others and a deviation between the predicted and the actual input is discovered. Pickering and Garrod (2013) argued that language users construct forward models (cf. Wolpert, Doya, \& Kawato, 2003) both to predict their own utterances and to predict the utterances of others. More precisely, when preparing to speak speakers are assumed to construct efference copies (i.e., impoverished representations) of their intended utterances and compare these copies to the output of the production implementer. Similarly, listeners are assumed to use forward production models to covertly imitate the speaker and predict the speaker's upcoming utterances. Thus, listeners generate predictions on the basis of what they would say next if they were the speaker.

To date, there is only indirect evidence supporting the contribution of production-based mechanisms to prediction. In the study by Mani and Huettig (2012) with 2-year old children mentioned above, the children listened to predictable and nonpredictable sentences such as "The boy eats a big cake" or "The boy sees a big cake" while looking at a display showing a cake and a bird. The toddlers showed anticipatory eye gaze to the cake before it was mentioned in the speech. More importantly, the children's predictive eye gaze correlated positively with the size of their production vocabulary size.

Electrophysiological evidence from studies conducted by Federmeier and colleagues is also consistent with the involvement of the production system in prediction. Federmeier, McLennan, De Ochoa, and Kutas (2002; Federmeier, Kutas, \& Schul, 2010; see also Ito et al., 2016) observed significant positive correlations between the amplitude of participants' ERP components that may be interpreted as indexing prediction and their production fluency as measured in the verbal fluency task. In this task, participants have to produce as many members of a given semantic category (e.g., animals or professions) or as many words beginning with a particular letter as possible within one minute. The number of words produced can be seen as an indicator of the participant's ability to quickly retrieve and produce words (for discussion see Luo et al., 2010; Shao et al., 2014). In a visual world study

\footnotetext{
${ }^{1}$ As for functional associations we prefer the term 'general associations' because we consider it to be an experience-based potential mechanism contributing to predictive language processing, whereas the term 'contingent probabilities' in our view is less mechanistic and more of a description of the likelihood of one word to come up given another word.
} 
Rommers, Meyer, and Huettig (2015) observed that stronger anticipatory bias to the target object was associated with higher verbal fluency scores.

In sum, there is accumulating evidence that some of the mechanisms involved in language production may also be involved in predicting upcoming language. Moreover, previous research demonstrated that the language users' production fluency, as assessed using the verbal fluency task, was predictive of their ability to predict upcoming information. In the present study we correlated participants' verbal fluency with their verb-mediated anticipatory eye gaze.

\section{Receptive Vocabulary Knowledge}

There is accumulating evidence that receptive vocabulary knowledge affects language-mediated anticipatory eye movements. For example, Borovsky, Elman, and Fernald (2012) tested children aged 3 to 10 listening to sentences such as "The pirate hides the treasure," in which the direct object referred to one of four objects on a computer screen, while the children's eye movements were tracked. The authors found that the time course of the children's anticipatory eye movements to the target was predicted by their receptive vocabulary scores, as assessed using the Peabody vocabulary test. Specifically, Borovsky et al. observed anticipatory looks to the target in children with high but not low vocabulary knowledge. The notion that receptive vocabulary knowledge, as assessed using the Peabody vocabulary test (Dunn \& Dunn, 1997), influences anticipatory language processing is corroborated by a recent visual world study with students by Rommers, Meyer, and Huettig (2015). As Borovsky and colleagues, they found that greater anticipatory bias to target objects (e.g., to the word 'moon' in sentences such as "In 1961, Neil Armstrong was the first man on to set foot on the moon") was associated with large vocabulary scores. Interestingly, as indicated above, Rommers et al. observed that anticipatory gaze to target objects was also linked to participants' production fluency, which is in line with an account in which multiple mechanisms and mediating factors jointly contribute to predictive language processing. An open question concerns how well production fluency and receptive vocabulary knowledge predict language-mediated anticipatory eye movements in the presence of other potential predictors (e.g., functional and general associations). Here, we aimed to answer this question. We used the Peabody vocabulary test to assess receptive vocabulary knowledge.

\section{Nonverbal Intelligence}

Finally, we examined the influence of nonverbal intelligence, on verb-mediated anticipatory eye gaze. The reason is that there is considerable psychometric evidence for the so-called ' $\mathrm{g}$-factor' (general intelligence) underlying mental abilities. The g-factor is a psychometric construct meant to account for the observation that performance of individuals in any type of cognitive task strongly predicts their performance in other cognitive tasks. Indeed there is a huge amount of experimental evidence for a general factor (see Deary, 2001, for review) necessitating that any study exploring individual differences in cognitive processing tests for such an influence. We correlated Raven's Advanced Progressive Matrices (Raven, Raven, \& Court, 1998), as a validated measure of non- verbal intelligence in schooled Western societies (Raven, 2000), with participants' verb-mediated anticipatory eye movements. Huettig and Janse (2016) observed that nonverbal intelligence as measured by performance in Raven's progressive matrices accounted only for very little unique variance in anticipatory eye gaze. Given these findings we predicted only minor influences of nonverbal intelligence on verb-mediated anticipatory eye gaze. However, Huettig and Janse used gender-marked articles rather than verb-specific information as cues that could be used for prediction. It is possible that nonverbal intelligence has a stronger impact on verb-mediated than gender-mediated anticipatory eye gaze and that we might therefore see a different pattern of results than observed in the earlier study.

In sum, the purpose of the current study was to examine five potential predictors of verb-mediated anticipatory eye gaze: functional associations, general word associations, production fluency, receptive vocabulary knowledge, and nonverbal intelligence. The predictable verb-noun pairs varied in the strength of functional associations (as established in a verb-noun typicality rating task) and general word associations (as determined in a free word association task). The influence of production abilities and receptive vocabulary was assessed by using the verbal fluency task and the Peabody vocabulary test, respectively. Finally, to assess the influence of nonverbal intelligence on anticipation behavior we asked participants to complete Raven's Advanced Progressive Matrices. Assessing this set of listener variables did not only allow us to estimate how strongly production fluency, receptive vocabulary knowledge, and nonverbal intelligence each contribute to explaining the variance within the participants' degree of verbmediated prediction, but also enabled us tease apart the influences of several potentially related cognitive abilities. For example, it is conceivable that participants' vocabulary knowledge feeds into their production fluency and also that nonverbal intelligence may be involved in both production fluency and vocabulary knowledge. Using all three of these as predictors thus increases the unique amount of variance that is explained by either variable over and above potential influences of the other variables.

\section{Experiment 1}

\section{Method}

Participants. Sixty-one members (mean age $=22, S D=3$ ) of the participant panel of the MPI for Psycholinguistics, all native speakers of Dutch, were paid for their participation. All participants had normal hearing and normal or corrected-to-normal vision. All participants gave written consent beforehand. The study was approved by the ethics board of the Faculty of Social Sciences of the Radboud University.

Stimuli. The eye-tracking experiment consisted of 40 items that each occurred in a predictable and in a nonpredictable condition. On each trial, the participants heard a sentence and saw a visual display consisting of four objects. On predictable trials, one of the four objects was predictable (e.g., "De man schilt op dit moment een appel," the man peels at this moment an apple); the remaining three objects were unrelated distractors (e.g., a candle, a radio, an owl, Figure 1, for an example). On nonpredictable trials, participants saw the same four objects as in the predictable condition but neither the target object nor any of the distractors 


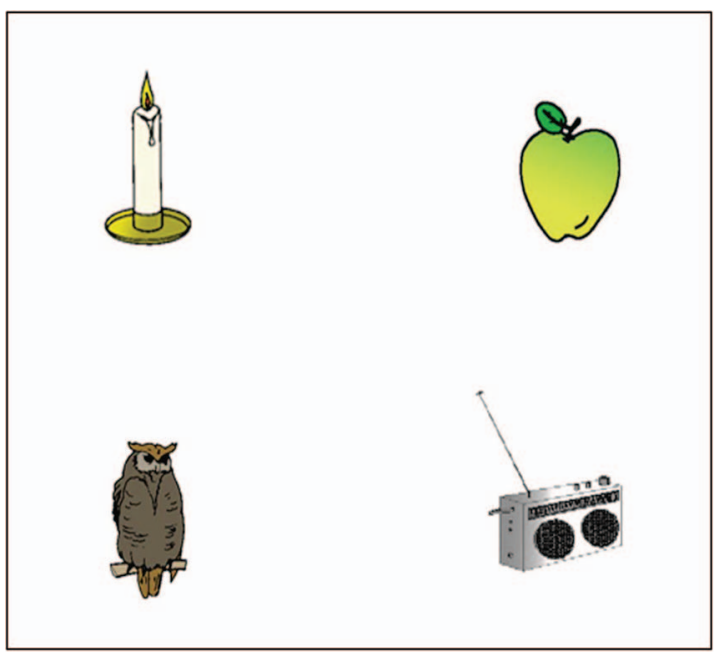

Figure 1. Example display for the target object apple with unrelated distractors. See the online article for the color version of this figure.

could be anticipated from the spoken sentential context (e.g., "De man tekent op dit moment een appel," the man draws at this moment an apple). All sentences had the same structure and number of words: The subject position was filled by "the man," and the adverbial "at this moment" separated verb and object. Using this padding between verb and target, we provided enough time for participants to make anticipatory eye movements. The resulting sentence construction is deemed quite natural by native speakers of Dutch. The predictable verb-noun pairs varied in general association strength. In the nonpredictable items, the general association strength was zero. General association strength was operationalized using a free association task for a larger set of verbs.

Free verb-noun association pretest. One hundred fifty-nine Dutch transitive verbs were selected from the CELEX database (Baayen, Piepenbrock, \& Gulikers, 1993) and evenly distributed across three lists. One hundred five native speakers of Dutch (mean age $=29, S D=14$ ), none of whom participated in any of the other rating studies or the main experiments, were randomly assigned one of the three lists and carried out an adapted version of the free association task (cf. Nelson, McEvoy, \& Schreiber, 2004). The participants were asked to read the verbs (one at a time) and write down the first three nouns that came to mind. The order of verbs on the lists was randomized for each participant. The pretest was conducted online using the WebExp package (Keller, Gunasekharan, Mayo, \& Corley, 2009). We used a continued (up to three words) rather than the single-word association task as this task has been shown to yield more reliable estimates of the associative relationship between lexical concepts (e.g., De Deyne, Navarro, \& Storms, 2013).

Each verb was read by at least 35 participants. For a given verb, the number of occurrences of a particular noun was counted and divided by the number of participants who had read that verb. This proportion served as the measure of general verb-noun association strength. There were 410 missing values ( $2.5 \%$ of the data) resulting from cells where participants had not provided any answers at all or no nouns. Forty predictable verb-noun pairs (e.g., 'schillen- appel,' peel-apple; see Appendix for all experimental verb-noun pairs) were selected. The mean general association strength in those pairs was .37 , ranging from .09 to .77 . In the experimental materials, the same nouns as in the predictable items were paired with neutral, nonpredictive transitive verbs (e.g., 'tekenen-appel,' draw-apple). The general association strength between verbs and nouns in these pairs was zero.

Cloze probability pretest. To be sure that predictable and nonpredictable verb-noun pairs were classified properly, we pretested the sentences for cloze probability (online, using the WebExp package). Thirty-five Dutch native speakers (mean age 21 years, $S D=2$ ), none of whom participated in other rating studies or the main experiments, were presented with the sentence fragments up to the object position (e.g., "The man verbs at this moment a ...") and were asked to fill in the final word which would best complete the sentence. The cloze probability was the proportion of participants who chose to complete the sentence fragment with the target word selected based on the pretest. On predictable items, the mean cloze probability for the target nouns was .39 ( $S D=.24$; ranging from .06 to .8$)$, in the nonpredictable items, it was zero. These results demonstrate that the target nouns could be predicted in the predictable but not in the nonpredictable sentence contexts.

Plausibility rating study. To ensure that both predictable and nonpredictable sentences depicted events that are likely to happen in real life, a pen-and-paper plausibility rating was carried out. Two lists were generated each containing 20 predictable and 20 nonpredictable sentences chosen at random. None of the target nouns appeared twice on the same list. Twenty implausible sentences, which had the same structure as the predictable and nonpredictable sentences, were added to each list. The 60 sentences were presented in random order. Twenty-four participants (visiting students from the University of Groningen, The Netherlands), 12 per list, who did not participate in other rating studies or the main experiments, were asked to estimate on a 1-10 scale how plausible the events described in the sentences were. The mean plausibility judgment for predictable sentences was $9.05(S D=.56)$; the mean plausibility judgment for nonpredictable sentences was $7.69(S D=$ .95). It is worth mentioning that although the plausibility ratings differed significantly between the predictable and the nonpredictable conditions, the latter items were overall still deemed very plausible. In fact, it is conceivable that differences in plausibility are a function of predictability such that predictable events are naturally rated more plausible (cf. DeLong et al., 2005; van Berkum et al., 2005).

Word length and frequency. Analyses were carried out on the length and frequency (using the SUBTLEX-NL database, Keuleers, Brysbaert, \& New, 2010) of the verbs and objects. Raw frequencies were transformed to Zipf values, as suggested by van Heuven, Mandera, Keuleers, and Brysbaert (2014). The mean number of letters of the inflected verb in the predictable sentences was $6(S D=2)$. The mean (Zipf-transformed) word frequency was 3.8 (one verb was not listed; $S D=$.6). In the nonpredictable sentences, the mean number of letters of the inflected verbs was 7 $(S D=2)$, and the mean (Zipf-transformed) word frequency was $4.2(S D=.6)$. The fact that the nonpredictable verbs were more frequent than the predictable verbs was most likely attributable to the nonpredictable verbs' less specific selectional restrictions. As we predicted facilitation effects for predictable rather than non- 
predictable items, this difference does not undermine our conclusions. The mean (Zipf-transformed) word frequency of the object nouns was $4.5(S D=.5)$.

Sentence recordings. The sentences were spoken with neutral intonation at a normal pace by a female native speaker of Dutch. Recordings were made in a sound-damped booth, sampling at 44 $\mathrm{kHz}$ (mono, 16 bit sampling resolution) and stored directly on computer. The mean sentence duration was $2800 \mathrm{~ms}(S D=214)$. Onsets and offsets of all words were marked using Praat (Boersma, 2002).

Display composition. To create the visual displays, 40 sets of four objects were composed each consisting of one target object and three distractor pictures which were unrelated to the other pictures in shape, semantics, and phonology of their names (see Figure 1, for an example). The pictures were selected from the database provided by Snodgrass and Vanderwart (1980) and colored in, or were drawn by an artist. We conducted two rating studies to assess the semantic and visual similarity between the concepts invoked by the target nouns and the distractor objects. The rating studies were necessary to ensure that the distractors were unrelated to the targets, as semantic and/or visual similarity can affect the participants' gaze pattern (cf. Huettig \& Altmann, 2005, 2007).

Visual and semantic similarity rating studies. Twelve participants (mean age $=23, S D=4$ ) provided semantic similarity ratings and 12 others (mean age $=22, S D=2$ ) provided visual similarity ratings. None of these participants took part in the main experiments. The study was conducted over the Internet using the WebExp package. In both rating studies, participants read 40 target nouns. Each target was paired with the four objects which were part of that item. For example, participants would read the word "apple" in the upper right corner of the screen and saw the four objects displayed in Figure 1 at the bottom, next to each other. The order was randomized. In the visual similarity rating study, participants were asked to judge how similar the typical visual shape of the concept denoted in the printed word was to the physical shape of the referents of the depicted objects, ignoring any similarity in meaning. In the semantic similarity rating, participants were asked to judge meaning similarity while ignoring shape similarity. A rating scale ranging from 0 (no similarity) to 10 (identical) was used in both tasks. As the object referred to by the written word was among the four pictures, we also obtained a measure of how well the object name fitted its visual representation. The results of the visual similarity rating confirmed that the target objects depicted the concepts invoked by the written words (mean target object rating $=9.91, S D=0.3$ ). The semantic similarity rating confirmed that the target objects matched the semantic representations invoked by the written words (mean target rating $=9.83, S D=0.41$ ). The mean distractor score in the visual similarity rating was $0.52(S D=0.56)$; in the semantic similarity rating it was $0.55(S D=0.4)$.

\section{Procedure.}

Eye-tracking experiment. The test session started with the eye-tracking experiment. The predictable and the nonpredictable versions of the 40 items were evenly distributed across two lists. None of the target nouns appeared twice on one list. Participants were randomly assigned one list and were seated in a soundshielded booth. Eye movements were tracked using an EyeLink 1000 remote desktop tracker sampling at $500 \mathrm{~Hz}$. A sticker was placed on the participant's forehead to monitor the position of the head relative to the tracker. The distance was held constant between 55 and $60 \mathrm{~cm}$. The eye-tracker was calibrated, and participants were instructed to listen to the sentences carefully and to not move their eyes away from the screen. We used a look-and-listen task (Huettig, Rommers, \& Meyer, 2011, for discussion), that is, the participants did not receive a specific viewing instruction. The spoken sentences were presented using loudspeakers. A trial was structured as follows: First, a central fixation dot appeared in the center of the screen for two seconds. The dot disappeared and the playback of the sentence started. The onset of the display was timed to one second prior to the occurrence of the verb in the speech signal. The four objects remained in view for the rest of the trial. The positions of the pictures were randomized across four fixed positions of a (virtual) $2 \times 2$ grid (see Figure 1 for an example). The time between the onset of the verb and the onset of the target noun was on average $1480 \mathrm{~ms}$. Each participant was presented with all 40 trials of one list. The order of trials was randomized automatically before the experiment. The eye-tracking experiment, including calibration, took approximately $10 \mathrm{~min}$. The data from participants' left or right eye (depending on the quality of the calibration) were analyzed in terms of fixations, saccades, and blinks, using the algorithm provided in the EyeLink software. Fixations were coded as directed to the target, to one of the three unrelated distractors, or elsewhere.

Production fluency task. Participants carried out a digitized version of the Dutch verbal fluency task (cf. van der Elst, van Boxtel, van Breukelen, \& Jolles, 2006). They were given two categories (animals and professions) and two letters ("p" and "m") and were instructed to produce as many words as possible belonging to the given category or beginning with the given letter within one minute. The category name or the letter was shown for three seconds before the screen went blank. Participants' answers were recorded. We excluded incorrect words and repetitions and calculated the average number of words across all four categories an individual produced within one minute (cf. Federmeier et al., 2002, 2010). The data of three participants had to be excluded because they misunderstood the task. We assessed the experiment-internal reliability of the verbal fluency task (cf. Abwender et al., 2001), as indicated by Cronbach's alpha, based on the number of correct words participants were able to produce within one minute, across the four categories (Table 1 for an overview of all reliability measures in Experiments 1, 2, and 3).

Functional associations. We followed Ferretti et al. (2001) and used a typicality rating task to operationalize functional associations. Each participant was presented with the same predictable and nonpredictable verb-noun pairs s/he was presented with in the eye-tracking experiment. Following the rating procedure suggested by Ferretti and colleagues, we embedded the pairs in the question

Table 1

Experiment-Internal Reliability Measures (Cronbach's $\alpha$ ) for the Individual Differences Measures in Experiments 1, 2, and 3

\begin{tabular}{lccc}
\hline Experiment/Test & Verbal fluency & Peabody & Raven's \\
\hline Experiment 1 & $\alpha=.751$ & $\alpha=.479$ & $\alpha=.844$ \\
Experiment 2 & $\alpha=.783$ & $\alpha=.695$ & $\alpha=.876$ \\
Experiment 3 & $\alpha=.617$ & $\alpha=.725$ & $\alpha=.885$ \\
\hline
\end{tabular}


"How common is it for a noun to be verbed?" (e.g., How common is it for an apple to be peeled?, Dutch translation, "Hoe waarschijnlijk is het voor een appel om geschild te worden?"). The participants were instructed to rate on a 1-10 scale how typical it was for the target and the three distractors used in the eye-tracking experiment to undergo the action implied by the verb. The items were presented to the participants in an Excel sheet. They typed the respective rating score next to each noun. The nouns appeared in a random order. Predictable and nonpredictable items were presented in random order as well. Log-transformed ratios between the rating for the target and the average rating for the three distractors were calculated for each item. A ratio of zero meant that target and unrelated distractors were rated to be equally typical; a ratio greater than zero indicated a bias toward the target. The mean ratio for the predictable items was $.71(S D=.23)$, ranging from .21 to 1 . The mean ratio for nonpredictable items was $.08(S D=$ .13) ranging from -.21 to .44 .

Raven's progressive matrices. We used a computerized version of Raven's advanced progressive matrices test (Raven, Raven, \& Court, 1998) to assess participants' nonverbal intelligence. Participants indicated which of eight possible shapes completed a matrix of geometric patterns by clicking on it with a mouse. Items could be skipped and were then shown again at the end of the test with the option to click an "I don't know" button. Participants had 40 min to complete 36 items. The time was indicated in the right top corner of the screen. A participant's score was the total number of correct responses. Experiment-internal reliability of the Raven's test (Cronbach's alpha; cf. Raven, 2000) was calculated based on participants' responses to the 36 test items (Table 1 for an overview).

Peabody vocabulary test. Participants' receptive vocabulary size was assessed using a digitized version of the Dutch Peabody picture vocabulary test (Dunn \& Dunn, 1997; Dutch translation by Schlichting, 2005). On each trial, participants heard a word and saw four numbered pictures on the screen. They indicated which of the pictures corresponded to the spoken word by typing the number $(1,2,3$, or 4$)$. Trials were presented in blocks of 12 , increasing in difficulty. The test ended if fewer than five correct responses were provided within one block. A percentile score was calculated based on Dutch norms. As not all participants were presented with the same number of trials, Cronbach's alpha, as the measure of experiment-internal reliability (Table 1, for an overview; cf. Dunn \& Dunn, 2007), was calculated based on the number of items for which sufficient data were available (Experiment $1=48$, Experiment $2=44$, Experiment $3=47$ ).

\section{Results}

The results of all experiments were analyzed using a magnitude estimation approach. This was motivated by a recent proposal (Cumming, 2014; see Huettig \& Janse, 2016), which advocates turning away from null-hypothesis testing toward interpreting results by using measures of effect sizes and confidence intervals. As has been shown empirically (cf. Fidler \& Loftus, 2009), this leads to a better interpretation of the results compared with a research report based on null hypothesis testing (see Cumming, 2012, 2014, for extensive discussion).

We plotted participants' eye movements for the period between the acoustic onset of the verb and the acoustic onset of the target word (time zero) plus $500 \mathrm{~ms}$. Figure 2 presents the fixation data of Experiment 1 in two ways: Panel A displays fixation proportions to the target object (solid lines) and to the averaged distractor objects (dashed lines) for the predictable (red) and the nonpredictable (blue) conditions. We computed by-participant confidence intervals $(95 \%)$ for each line at every sampling step (2 ms). The area between the lower and the upper bounds is shaded in gray. In Panel B, we log-transformed the fixation proportions and subtracted fixations to the three distractor objects from fixations to the target objects in the predictable (red line) and nonpredictable (blue line) condition (cf. Arai, van Gompel, \& Scheepers, 2007). A difference of zero means that target and averaged distractors were fixated equally often, and a difference greater than zero means that more fixations were made to the target object. By-participant confidence intervals were calculated for each sampling step, based on the mean of the difference between target and distractors.

Both panels show that participants' likelihood of fixating the target objects in the predictable condition increased already one

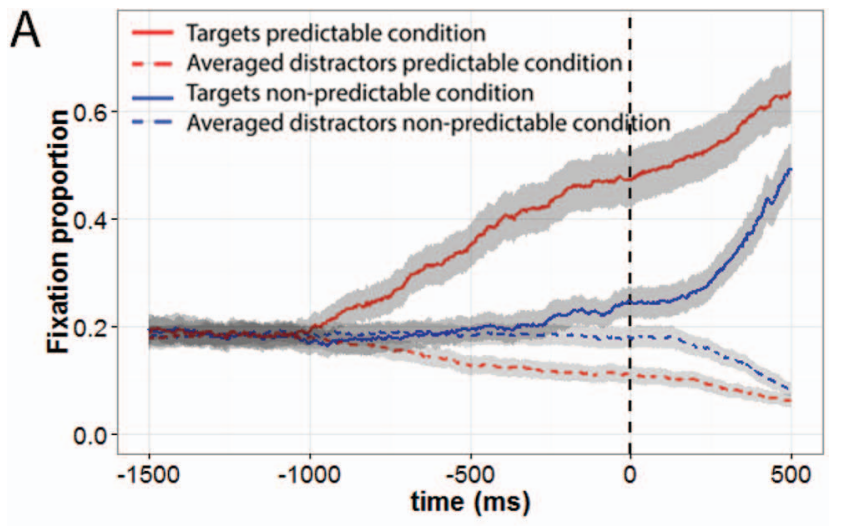

B

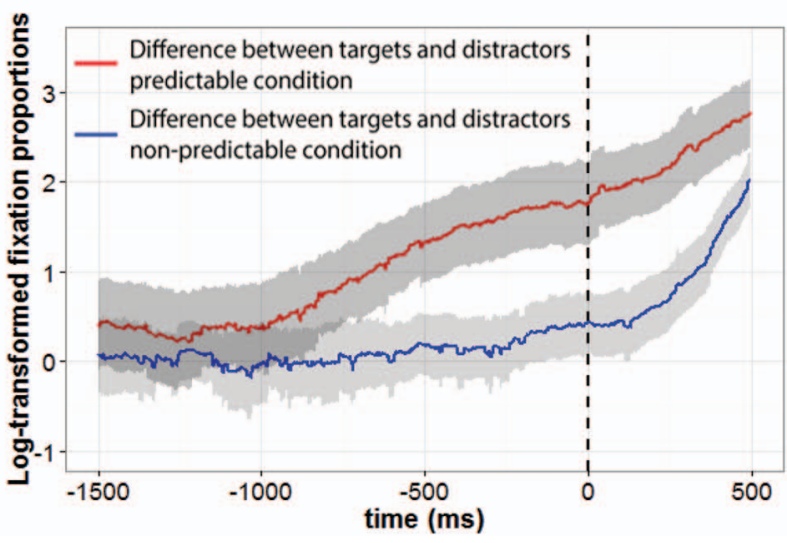

Figure 2. Results of Experiment 1. Panel A plots the fixation proportions for target and averaged distractor objects in the predictable and nonpredictable condition. Panel B plots the difference between log-transformed fixation proportions for target and distractor objects for predictable and nonpredictable conditions. Confidence intervals (95\%), calculated for each sampling step, are shaded in gray. The critical window spanned the time between the acoustic onset of the verb and the acoustic onset of the target word in the speech signal $(M=1.5 \mathrm{~s})$. Time zero (vertical dashed line) indicates the onset of the target word. See the online article for the color version of this figure. 
second before the target word occurred in the speech signal. This suggests that participants anticipated the upcoming targets very early, shortly after the verb had been heard. However, the same target objects referred to in the nonpredictable condition only attracted increased overt visual attention after the onset of the spoken target noun. The confidence intervals indicate that the by-participant variance was smaller in the nonpredictable and larger in the predictable condition, which suggests variation in participants' tendency to predict.

Figure 3 displays the variability in anticipating the target object in the predictable and in the nonpredictable conditions. The two scatter plots show each participant's mean difference between looks to the target and looks to the averaged distractors during the critical time window in the respective conditions. Standard deviation error bars indicate within-participant variation. A mean difference of zero indicates equal looks to target and distractors. The overall mean in the predictable conditions was $.2(S D=.31)$; the overall mean in the nonpredictable conditions was .02 $(S D=.24)$.

We carried out multiple linear regression analyses (by participants and items) on the predictable trials of Experiment 1 to estimate the contribution of general and functional associations, production fluency, receptive vocabulary, and nonverbal intelligence to verb-mediated anticipatory eye movements. For each predictor, we report both unstandardized and standardized betas as well as $95 \%$ confidence intervals for the unstandardized betas and collinearity tolerance $(\mathrm{ct})$. The standardized betas represent the measure of effect size and are roughly comparable to Pearson's $r$. Note that our main interest lies in comparing the effect sizes of the various predictors and their stability across different experiments.

To calculate the dependent variable, we divided each participant's proportion of looks to the target during the onset-verbonset-target period ${ }^{2}$ on a given trial by that participant's proportion of looks to the averaged distractors during the same time window. The resulting values were log-transformed. Prior to the division and log-transformation fixation proportions of 0 or 1 were replaced with 0.01 and 0.99 , respectively (cf. Macmillan \& Creelman, 1991). The data were aggregated by participant and by item yielding average scores for each participant and for each item. We calculated the split-half reliability (Spearman-Brown coefficient) for the dependent variable for the predictable and the nonpredictable conditions. As we had two experimental lists, split-half reliability was calculated for each list separately (predictable condition: List $1=.708$, List $2=.591$; nonpredictable condition: List $1=.405$, List $2=.139$.

By-participant regression analysis. The participants' verbal fluency scores, their Peabody vocabulary scores, and their Raven's nonverbal intelligence scores were simultaneously entered as predictors into the regression analysis (Table 2 for an overview of the correlations among the predictors in all experiments). The model with an $R^{2}$ of .203 showed the following independent contributions to participants' predictive eye gaze (see Table 3 for an overview of the standardized betas in all experiments): verbal fluency (unstandardized $\beta=.057$, SE $\beta=.026$, CI $[.005, .110]$; standardized $\beta=$ $.269, c t=.99$; see Figure 4 , for scatter plots), Peabody vocabulary (unstandardized $\beta=.009$, SE $\beta=.005$, CI $[-.001, .019]$; standardized $\beta=.238$, ct $=.799$ ), Raven's nonverbal intelligence (unstandardized $\beta=.024, \operatorname{SE} \beta=.016$, CI [-.009, .057]; standardized $\beta=.199, c t=.794)$.
Upon reviewer request, we carried out an additional analysis on the amount of variance explained by the listener variables in the predictable and nonpredictable conditions. We fitted a linear mixed-effects model in $\mathrm{R}$ (R Development Core Team, 2011) using the lme4 package (Bates et al., 2015). The dependent variable (log-transformed fixation ratios) was calculated as described above. The model further contained the fixed factor Condition (predictable vs. nonpredictable), as well as participants' verbal fluency, receptive vocabulary, and Raven's scores as continuous predictors (scaled and centered). As Raven's and Peabody scores were correlated, the former were residualized. Participants and Items were included as random factors, each with random intercepts. ${ }^{3}$ Crucially, interactions between Condition and each of the three listener variables were added. The nonpredictable condition was put on the intercept. The best-fitting mixed-model revealed the following effects, which were very similar to the results of the regression analyses: Condition $\beta=.99, S E \beta=.078, t=12.702$, Verbal Fluency $\times$ Condition $\beta=.21, S E \beta=.079, t=2.688$, Peabody $\times$ Condition $\beta=.31, S E \beta=.079, t=3.945$, Raven's $\times$ Condition $\beta=.15, S E \beta=.089, t=1.67$.

By-item regression analysis. The measures of the items' functional and general associations, as assessed using a verb-noun typicality rating task and free verb-noun associations, respectively, were entered simultaneously into the regression analysis. The correlation between both variables was $r=.25$. The model with an $R^{2}$ of .222 revealed the following individual contributions to explaining the variance in the likelihood of predictive looks made to an item: functional associations (unstandardized $\beta=$ 1.646, SE $\beta=.508$, CI [.616, 2.676]; standardized $\beta=.485, c t=$ 938; Figure 4, for scatter plots), general word associations (unstandardized $\beta=-.748, S E \beta=.673$, CI $[-2.111, .615]$; standardized $\beta=-.166, c t=.938$ ).

\section{Discussion}

We found evidence for robust and early effects of target noun anticipation given predictable verbs, replicating earlier research. The same nouns were not anticipated following nonpredictable verbs. The effect size measure (standardized betas) suggests that in the by-participant analyses receptive vocabulary and production fluency each accounted for large amounts of unique variance. A smaller portion of variance was explained by nonverbal intelligence. Moreover, the mixed-effects model analysis revealed that none of the measures predicted eye gaze in the nonpredictable condition. The results of the by-item regression analyses showed that functional associations contributed the largest amount of unique variance to explaining variability in predictive eye gaze.

The substantial influence of functional associations on anticipatory language processing suggests that the more typical a target noun was rated to undergo the action implied by the verb the higher the likelihood of predictive looks to that item. General word associations did not predict anticipatory eye movements. The modulating influence of participants' production fluency scores on their predictive eye gaze is consistent with previous evidence that

\footnotetext{
${ }^{2}$ We added $200 \mathrm{~ms}$ to both verb and target onset to adjust for the time it takes to program and launch a saccadic eye movement (Saslow, 1967).

${ }^{3}$ More complex model structures (i.e., adding Condition as random slopes by participants and items) failed to converge.
} 

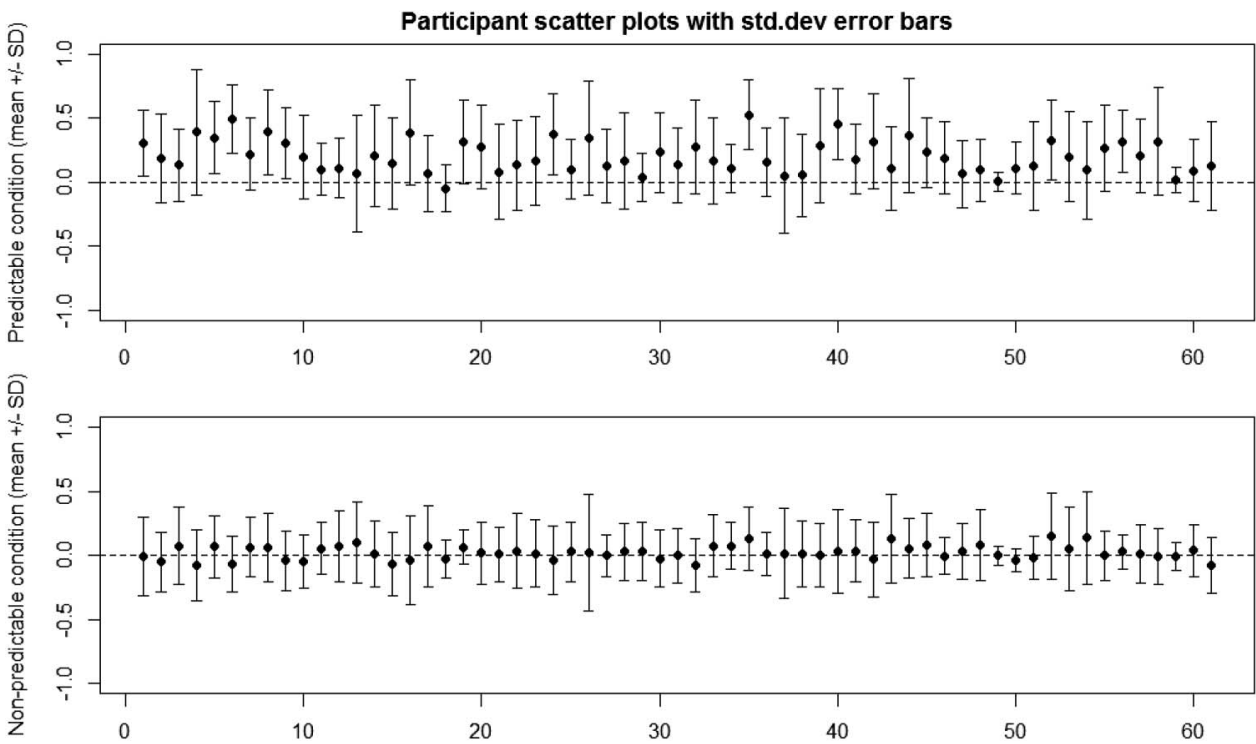

Figure 3. Within-participant and between-participants variation in fixation behavior in Experiment 1. The plots show each participant's mean difference (and standard deviation error bars) between looks to the target and looks to the averaged distractors in the predictable and nonpredictable conditions during the critical time window. A mean difference of zero means equal looks to target and distractors; a positive mean difference implies a bias for the target.

participants' language production abilities are important for predictive language processing (Federmeier et al., 2002, 2010; Mani \& Huettig, 2012; cf. Dell \& Chang, 2013; Pickering \& Garrod, 2007, 2013). The positive relationship between participants' production fluency scores and their predictive gaze revealed that participants who produced more words within a minute showed more verb-mediated anticipatory gaze behavior. The modulating influence of participants' Peabody scores on their predictive eye gaze is consistent with the notion that receptive vocabulary impacts anticipatory language processing.

Verb-noun typicality ratings from naive participants. One could argue that functional associations predicted the likelihood of predictive looks made to an item so well because the ratings were given by the same sample of participants who had previously participated the visual world experiment. Perhaps their experience in the eye-tracking experiment somehow affected

Table 2

Correlations Among Participant Variables in Experiments 1, 2, and 3

\begin{tabular}{lllc}
\hline Experiment/Test & Peabody & Raven's & $\begin{array}{c}\text { Cross-modal } \\
\text { priming (Exp. 2) }\end{array}$ \\
\hline Experiment 1 & & & \\
$\quad$ Verbal fluency & $r=.012$ & $r=-.082$ & - \\
$\quad$ Peabody & & $r=.446$ & - \\
Experiment 2 & & & $r=.014$ \\
$\quad$ Verbal fluency & $r=.189$ & $r=.154$ & $r=.234$ \\
Peabody & & $r=.337$ & $r=.338$ \\
$\quad$ Raven's & & & - \\
Experiment 3 & $r=.242$ & $r=.149$ & - \\
$\quad$ Verbal fluency & $r=.431$ & \\
$\quad$ Peabody & & $r=$ & \\
\hline
\end{tabular}

their ratings. To assess this possibility, we asked an independent sample of 20 native speakers of Dutch (mean age $=21$, $S D=2$ ) to carry out the typicality ratings in the same way as described above. The mean verb-noun typicality ratio for the predictable items was $.65(S D=.21)$, ranging from .14 to .98 . The mean ratio for nonpredictable items was $.06(S D=.13)$ ranging from -.20 to .38 . We then reran the by-items regression analysis including the measure of general associations and the newly collected measure of functional associations $\left(R^{2}=\right.$ .232). As before, general word associations did not explain much of the variance in predictive eye gaze (unstandardized $\beta=-.613, S E \beta=.659$, CI $[-1.948, .722]$; standardized $\beta=-.136$ ). The influence of the newly collected verb-noun typicality ratings on the dependent variable was very similar to the influence of the verb-noun typicality ratings stemming from the participants who had taken part in the eye-tracking before (independent sample: unstandardized $\beta=1.767, S E \beta=.531$, CI $[.691,2.844]$; standardized $\beta=.488$ vs. eye-tracking participants: unstandardized $\beta=1.646, S E \beta=.508$, CI [.616, 2.676]; standardized $\beta=.485$ ). This suggests that the previous ratings were, if at all, only weakly influenced by memory effects or familiarity with the materials resulting from having participated in the visual world experiment before. In the following by-item analyses we thus used the verb-noun typicality ratings obtained from the participants of Experiment 1 .

Free noun-verb association. Why did we not observe any influence of general word associations on verb-mediated eye gaze? As in most previous eye-tracking experiments, participants were given some preview of the visual scene. During that time, they could retrieve information about the four objects and activate associated verbal knowledge. Thus, the visual preview may have provided a Head Start for the preactivation of conceptual and 
Table 3

Unique Variance Explained by Each of the Five Predictor Variables in Experiment 1, 2 and 3, and the Combined Data of Experiment 1 and 2

\begin{tabular}{|c|c|c|c|c|}
\hline Variable & $\begin{array}{l}\text { Experiment } 1 \\
\text { long preview }\end{array}$ & $\begin{array}{l}\text { Experiment } 2 \\
\text { long preview }\end{array}$ & $\begin{array}{l}\text { Experiment } 1 \text { and } 2 \\
\text { combined long preview }\end{array}$ & $\begin{array}{l}\text { Experiment } 3 \\
\text { short preview }\end{array}$ \\
\hline \multicolumn{5}{|l|}{ By-participant regression } \\
\hline Non-verbal IQ (Raven's) & $\beta=.199$ & $\beta=-.065$ & $\beta=.06$ & $\beta=.092$ \\
\hline Receptive vocabulary (Peabody vocabulary test) & $\beta=.238$ & $\beta=.226$ & $\beta=.242$ & $\beta=.277$ \\
\hline Production ability (Verbal fluency task) & $\beta=.269$ & $\beta=.194$ & $\beta=.213$ & $\beta=-.063$ \\
\hline \multicolumn{5}{|l|}{ By-item regression } \\
\hline Functional associations (verb-noun typicality rating) & $\beta=.485$ & $\beta=.523$ & $\beta=.553$ & $\beta=.491$ \\
\hline General associations (free verb-noun association) & $\beta=-.166$ & $\beta=.036$ & $\beta=-.085$ & $\beta=-.026$ \\
\hline
\end{tabular}

Note. Standardized betas from by-participant and by-item analyses are provided as the measure of effect size.

lexical information associated with the objects and may have overridden the effects of general verb-noun associations.

To assess this hypothesis, we carried out another free association task on the target nouns used in the eye-tracking experiment. If general noun-verb rather than the verb-noun associative relationships were crucial for the eye-tracking results, we should observe a positive relationship between the general noun-verb association strength of an item and the likelihood of anticipatory eye movements made to that item. Forty-four Dutch participants who had not taken part in any of the rating studies or the main experiment were asked to read the 40 target nouns and note down the first three verbs that came to mind. The parameters and the analysis were identical to the free verb-noun association task. The mean general noun-verb association strength in the predictable condition was .29 ( $S D=.3)$ ranging from 0 to .98 ; in the nonpredictable condition, it was .011 $(S D=.04)$. We entered the measures of general noun-verb associations, general verb-noun associations and functional associations into a by-item regression analysis $\left(R^{2}=.223\right)$. Similar to general verb-noun associations in the previous analysis, general noun-verb associations did not

\section{Participant correlations}
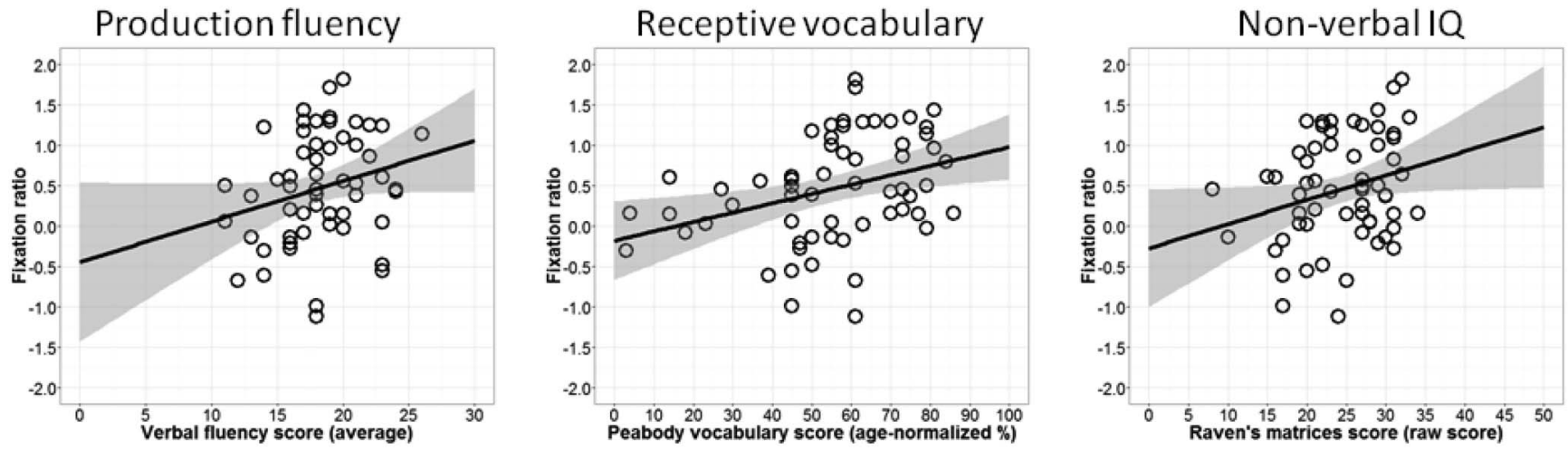

Item correlations
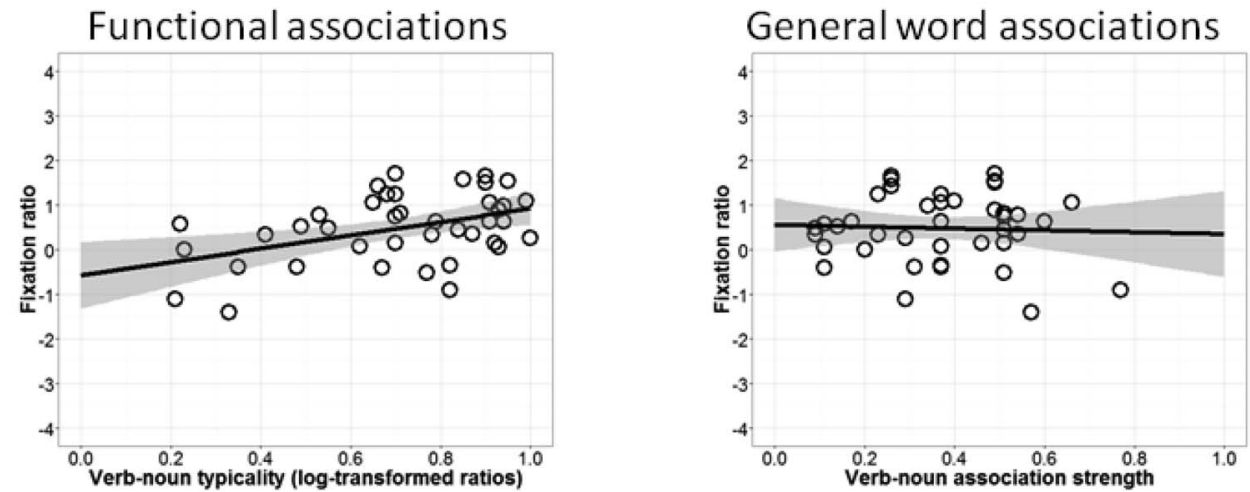

Figure 4. Scatter plots showing participant and item correlations in Experiment 1. 
explain much unique variance of the anticipatory eye gaze (unstandardized $\beta=-.271, S E \beta=1.205$, CI $[-2.714,2.172]$; standardized $\beta=-.035)$. The contributions of the other variables were similar to the previous analysis (functional associations: unstandardized $\beta=1.689, S E \beta=.55$, CI [.574, 2.803]; standardized $\beta=.497$; general verb-noun associations: unstandardized $\beta=-.746, S E \beta=.681$, CI $[-2.128, .636]$; standardized $\beta=-.166)$.

In sum, Experiment 1 demonstrated that production fluency, receptive vocabulary, and functional associations were important predictors of verb-mediated anticipatory eye movements.

\section{Experiment 2}

The aim of Experiment 2 was to replicate the results of Experiment 1 . This decision was motivated by two considerations: First, we aimed to assess the reliability of the observed regression effects in order not to capitalize on spurious observations. Second, we wanted to estimate the contribution of object-verb priming to anticipatory eye movements in a more direct way. Recent evidence suggests that visual objects exert a substantial influence on the recognition of auditory linguistic input. McQueen and Huettig (2014) showed that lexical decision times to spoken target nouns were faster when the words were preceded by semantically related picture primes (e.g., arrow-"sword"). The nature of the trials in the eye-tracking experiment in the current study was similar to the nature of the cross-modal priming trials in McQueen and Huettig's study. This motivated us to explore the possibility of object-verb priming in our trials and its potential influences on anticipatory eye movements.

Experiment 2 was run in two sessions. In Session 1, participants took part in the same eye-tracking experiment as in Experiment 1 and completed the Peabody vocabulary test and the verbal fluency task. In Session 2, two weeks later, we asked the same participants to complete the Raven's nonverbal intelligence test and participate in a cross-modal object-verb priming experiment, in which we used the same materials as in the eye-tracking experiment. The primes consisted of the target objects used in the eye-tracking experiment (e.g., apple), and the targets were the verbs presented auditorily just as in the eye-tracking experiment (e.g., "peel"). As the trials in the eye-tracking experiment and in the priming experiment were comparable, we could examine the effects of objectverb priming systematically. Based on the results of the free noun-verb association task, we predicted faster RTs in a lexicaldecision task pertaining to predictable rather than to nonpredictable items. If this kind of priming had an influence on participants' anticipatory eye movements, their priming effects should correlate positively with their likelihood of anticipatory fixations in the eye-tracking experiment. Similarly, the strength of the priming effect for an item in the cross-modal priming experiment should contribute to explaining variance in the by-item regression analyses of predictive looks to the target objects in the eye-tracking experiment.

\section{Method}

Participants. Sixty-one members (mean age $=21$ years of life, $S D=3$ ) of the participant panel of the MPI for Psycholinguistics, all native speakers of Dutch, were paid for their partici- pation. All participants were right-handed, had normal hearing, and normal or corrected-to-normal vision. All participants gave written consent beforehand. None of them had taken part in any of the norming studies or Experiment 1. Because one participant did not come back for the second test session we excluded their data from all tasks in Session 1. The final sample therefore comprised 60 participants.

\section{Stimuli and procedure.}

Session 1. In Session 1, participants carried out the same eye-tracking experiment as in Experiment 1. Because the eyetracker used in the first experiment was unavailable, we used a tower mounted EyeLink 1000 tracker. The tracker sampled at 1000 Hz. Participants were asked to put their chin on a chin rest. The distance between their heads and the screen was fixed at $75 \mathrm{~cm}$. Instructions and subsequent eye-tracker calibration were identical to Experiment 1.The eye-tracking experiment was followed by the Peabody vocabulary test and the verbal fluency task. Due to task misunderstanding and a technical error, the verbal fluency data of two participants could not be analyzed. Session 1 took approximately 35-45 min.

Session 2. The first experiment of Session 2 was the crossmodal object-verb priming experiment, which featured picture primes and auditory targets. On each trial, participants were asked to judge whether or not a spoken inflected verb was an existing Dutch word. The verbs (extracted from the recordings used in the eye-tracking experiment) were preceded by object primes which were on $25 \%$ of the trials (i.e., the 20 predictable items) related to the verbs. In total, the experiment consisted of 80 experimental and 40 filler items. Each participant saw the same 40 object-verb pairs (20 predictable and 20 nonpredictable) from the list s/he was presented with in the eye-tracking experiment. Those 40 pairs served as experimental items and required a Yes-response. Yesresponses were provided using the right (dominant) hand on a button box. The inflected verbs in the predictable and the nonpredictable condition were similar in length.

Filler items which required a No-response were constructed by selecting 40 additional object primes and pairing them with 40 pseudoverbs derived from existing Dutch verbs by replacing a single letter. The pseudoverbs were embedded in a sentence template similar to the experimental stimuli and spoken by the same speaker. Recordings of those sentences were made and the pseudoverbs were extracted using Praat. Filler items were the same for all participants. Two lists with 80 trials each were generated and pseudorandomized prior to the experiment.

Each participant was presented with all 80 trials on one list. The structure and timing in a trial were similar to Ferretti, McRae, and Hatherell (2001) and were as follows: A plus-sign appeared in the center of the screen for $250 \mathrm{~ms}$. Subsequently, the prime object (e.g., a picture of an apple) was presented for $200 \mathrm{~ms}$. A visual mask used to minimize effects of visual memory was shown for 50 ms before the target (e.g., "schilt," peels) was played back. A trial was terminated by the participant's response. Participants received immediate visual feedback for incorrect responses. The intertrial interval was $1500 \mathrm{~ms}$. The experiment took approximately five minutes. Incorrect responses and RTs greater than $1300 \mathrm{~ms}$ (more than twice as long as the expected mean reaction time (RT) based on similar studies, see Ferretti, McRae, \& Hatherell, 2001; McRae, Hare, Elman, \& Ferretti, 2005) to experimental trials were removed from the analysis (a total of $6.2 \%$ of the data). Because of 
an error, the logfiles of two participants were not saved. In the regression analysis, these cells were left empty. After the priming experiment, the participants completed Raven's progressive matrices test.

\section{Results}

Eye-tracking experiment. The eye-tracking data were analyzed as in Experiment 1. Figure 5 shows time-course graphs plotting the fixation proportions for target and distractor objects for the predictable and nonpredictable condition (Panel A) and the difference between log-transformed fixation proportions for target and distractor objects in the predictable and nonpredictable conditions (Panel B). As in Experiment 1, by-participant CIs for the respective objects/conditions were calculated for each sampling step $(1 \mathrm{~ms})$ and added to the plots. The pattern of fixations looks
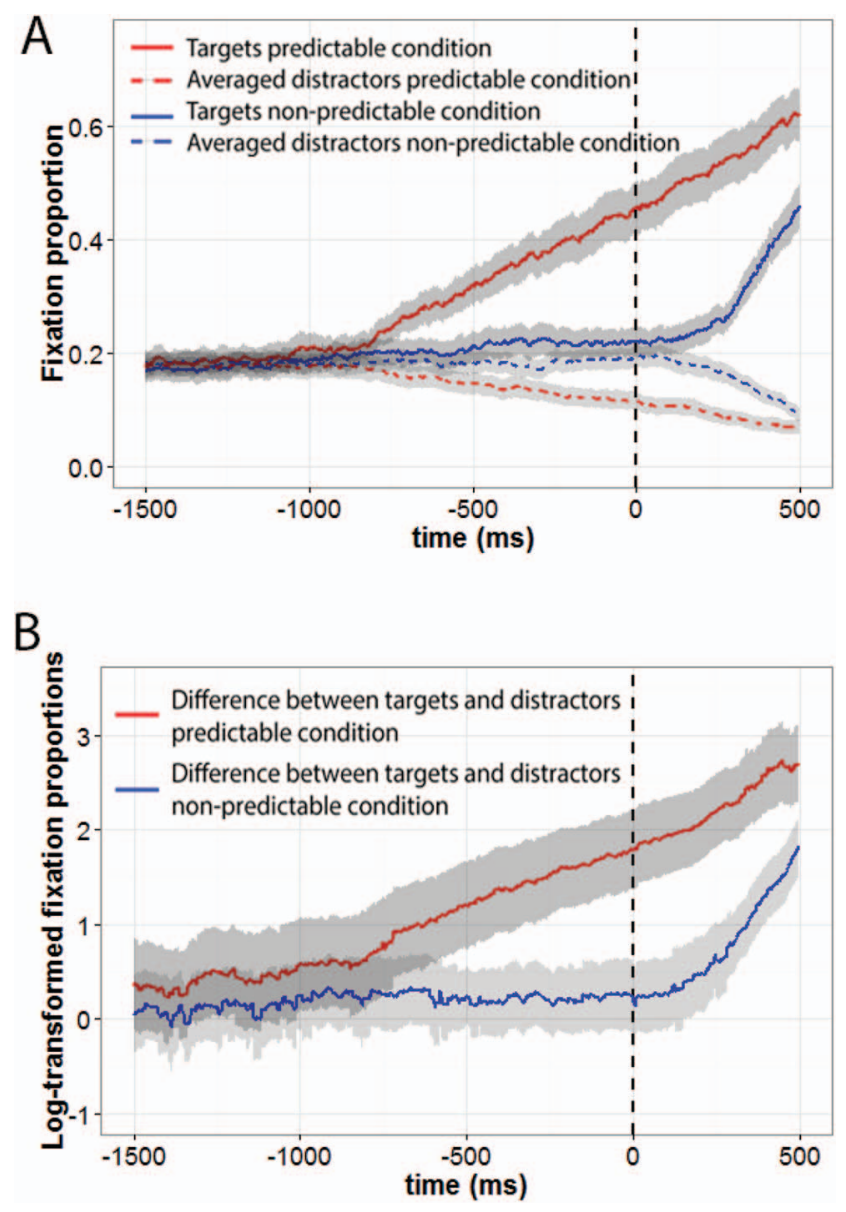

Figure 5. Results of Experiment 2. Panel A plots the fixation proportions for target and averaged distractor objects in the predictable and nonpredictable condition. Panel B plots the difference between log-transformed fixation proportions for target and distractor objects for predictable and nonpredictable conditions. Confidence intervals (95\%), calculated for each sampling step, are shaded in gray. The critical window spanned the time between the acoustic onset of the verb and the acoustic onset of the target word in the speech signal $(M=1.5 \mathrm{~s})$. Time zero (vertical dashed line) indicates the onset of the target word. See the online article for the color version of this figure. very similar to that in Experiment 1: In the predictable condition, participants anticipated the target noun and fixated upon the respective picture shortly after they had heard the verb, roughly one second prior to the target word onset. In the nonpredictable condition, there was no difference in looks to the target object and the unrelated distractors during the time period starting at the onset of the verb until the onset of the target noun. Only after target noun onset, participants gazed more at the target picture than at the unrelated distractors.

As for Experiment 1, we plotted within-participant and betweenparticipants variation as the difference between each participant's likelihood of looks to target and looks to the averaged distractors in the predictable and nonpredictable conditions (see Figure 6). The overall mean in the predictable conditions was $.17(S D=.28)$; the overall mean in the nonpredictable condition was $.02(S D=$ .24). As before, split-half reliability for both experimental lists in Experimental 2 was calculated (predictable condition: List $1=$ .528 , List $2=.582$; nonpredictable condition: List $1=-.102$, List $2=-.251)$.

Cross-modal object-verb priming. Reaction times to predictable items were on average $17 \mathrm{~ms}$ faster than RTs to nonpredictable items. The mean RT in the predictable condition was 734 $\mathrm{ms}(S D=163[740.9,761.1])$, and the mean RT in the nonpredictable condition was $751 \mathrm{~ms}(S D=170, \mathrm{CI}$ [724.3, 743.7]). We calculated each participant's and each item's priming effect by subtracting a participant's or an item's mean RT in the predictable condition from that participant's or that item's mean RT in the nonpredictable condition. Note that for our argument the overall priming effects are less important than the priming effects for individual participants and items and their contributions to anticipatory eye movements.

By-participant regression analysis. The by-participant regression analysis $\left(R^{2}=.1\right)$ for participants' gaze in the predictable condition was based on the same variables as in Experiment 1plus the by-participant cross-modal object-verb priming effects (see Figure 7 for scatter plots. The model revealed the following individual contributions (see Table 3 for a summary): verbal fluency (unstandardized $\beta=.033, S E \beta=.023$, CI $[-.013, .079]$; standardized $\beta=.194, c t=.951$ ), Peabody vocabulary (unstandardized $\beta=.009$, SE $\beta=.006$, CI $[-.002, .02]$; standardized $\beta=$ $.226, c t=.849$ ), Raven's nonverbal intelligence (unstandardized $\beta=-.007$, SE $\beta=.015$, CI $[-.038, .024]$; standardized $\beta=-.065, c t=.805$ ), cross-modal priming effect (unstandardized $\beta=.001, S E \beta=.002$, CI $[-.003, .004]$; standardized $\beta=$ $.037, c t=.866)$.

As for Experiment 1, we carried out a mixed-effects model analysis on the amount of variance explained by the listener variables in the predictable and the nonpredictable conditions. The model was identical to that described in Experiment 1, except that it additionally contained participants' cross-modal priming effects as a continuous predictor (scaled and centered). The best-fitting mixed-model revealed the following effects: Condition $\beta=.94$, $S E \beta=.079, t=11.97$, Verbal Fluency $\times$ Condition $\beta=.13$, $S E \beta=.08, t=1.609$, Peabody $\times$ Condition $\beta=.2, S E \beta=.084$, $t=2.409$, Raven's $\times$ Condition $\beta=-.003$, SE $\beta=.087$, $t=-.037$, Cross-Modal Priming $\times$ Condition $\beta=.03, \operatorname{SE} \beta=$ $.092, t=.345$.

By-item regression analysis. Predictive gaze was regressed on the measures of verb-noun typicality, general verb-noun and 

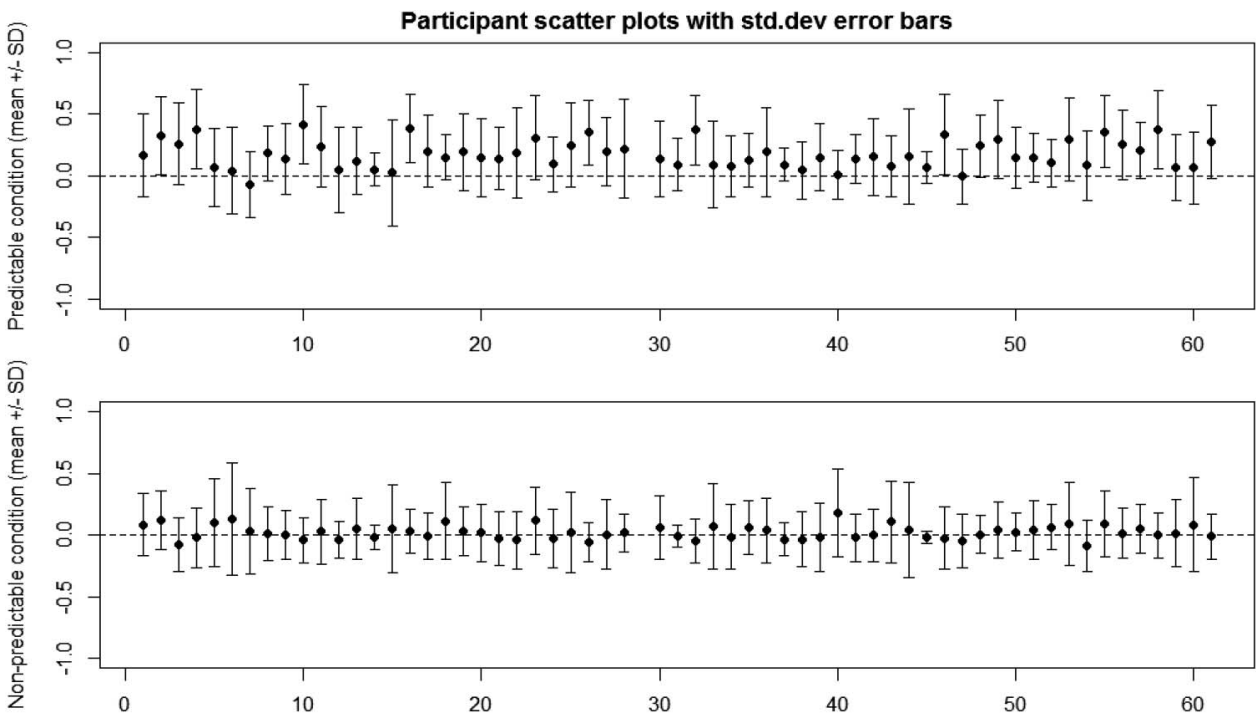

Figure 6. Within-participant and between-participants variation in fixation behavior in Experiment 2. The plots show each participant's mean difference (and standard deviation error bars) between looks to the target and looks to the averaged distractors in the predictable and nonpredictable conditions during the critical time window. A mean difference of zero means equal looks to target and distractors; a positive mean difference implies a bias for the target.

noun-verb association strength, and the items' cross-modal priming effects (correlations among predictors: verb-noun typicality and noun-verb association strength, $r=.362$; verb-noun typicality and cross-modal priming effect, $r=.084$; verb-noun and noun-verb association strength, $r=.1$; verb-noun association strength and cross-modal priming effect, $r=-.03$; noun-verb association strength and cross-modal priming effect, $r=.32$ ). As in Experiment 1, functional associations contributed most to explaining variance within the dependent variable (unstandardized $\beta=1.484$, SE $\beta=.434$, CI $[.603,2.365]$; standardized $\beta=.523$, $c t=.823$; see Figure 7 , for scatter plots). The unique contributions of the other variables were rather low (general verb-noun associations: unstandardized $\beta=.134, S E \beta=.539$, CI [-.96, 1.228]; standardized $\beta=.036, c t=.934$; general noun-verb associations: unstandardized $\beta=.592, \operatorname{SE} \beta=1.001$, CI $[-1.441,2.624]$; standardized $\beta=.093 \mathrm{ct}=.784$; cross-modal priming effect: unstandardized $\beta<.001$, SE $\beta=.001$, CI [-.002, .002]; standardized $\beta=-.013, c t=.894)$. The $R^{2}$ of that model was .327 . We observed a moderate positive correlation between the items' general noun-verb association strength and their cross-modal object-verb priming effects $(r=.32$, CI [.008, .631]).

\section{Discussion}

The eye-tracking results of Experiment 2 replicated the prediction effect found in Experiment 1: Participants shifted their overt visual attention to the target objects already one second before the targets were mentioned. Likewise, by-participant and by-item regression analyses yielded results similar (though slightly lower in effect size) to those in Experiment 1: Receptive vocabulary and, to a lesser extent, production fluency explained considerable unique variance in verb-mediated anticipatory eye movements in the by-participant analysis. Whereas
Experiment 1 had yielded some evidence for an effect of nonverbal intelligence on anticipatory eye gaze, this effect disappeared completely in Experiment 2. As in Experiment 1, none of the listener variables predicted much variance in participants' gaze in the nonpredictable condition. By items, functional associations accounted for the largest proportion of unique variance in predictive eye gaze.

Experiment 2 explored the influence of object-verb priming on predictive eye gaze. In a lexical decision experiment the target objects primed the recognition of spoken verbs, similar to previous research (McQueen \& Huettig, 2014). The regression analyses, however, showed that the participants' and the items' cross-modal priming effects did not explain much of the variance in anticipatory eye gaze.

With regard to the contribution of general word associations, it is conceivable that we did not observe any influence on predictive processing because anticipatory eye movements were influenced by both general noun-verb and general verb-noun associative priming. Our measures only captured each influence individually and not their combined effect. To assess this possibility, we added the values of each item's general noun-verb association strength and verb-noun association strength yielding a combined measure of general association strength. Subsequently, we regressed predictive gaze (using the combined data of Experiment 1 and 2) on the measure of functional associations and the combined measure of general associations. The model $\left(R^{2}=.294\right)$ showed that functional associations still explained a large amount of unique variance in predictive eye gaze (unstandardized $\beta=1.634, S E \beta=$ .432 , CI $[.758,2.51]$; standardized $\beta=.565$ ) but the combined general verb-noun and noun-verb association strength did not (unstandardized $\beta=-.213, S E \beta=.473$, CI $[-1.172, .745]$; standardized $\beta=-.067)$. 


\section{Participant correlations}
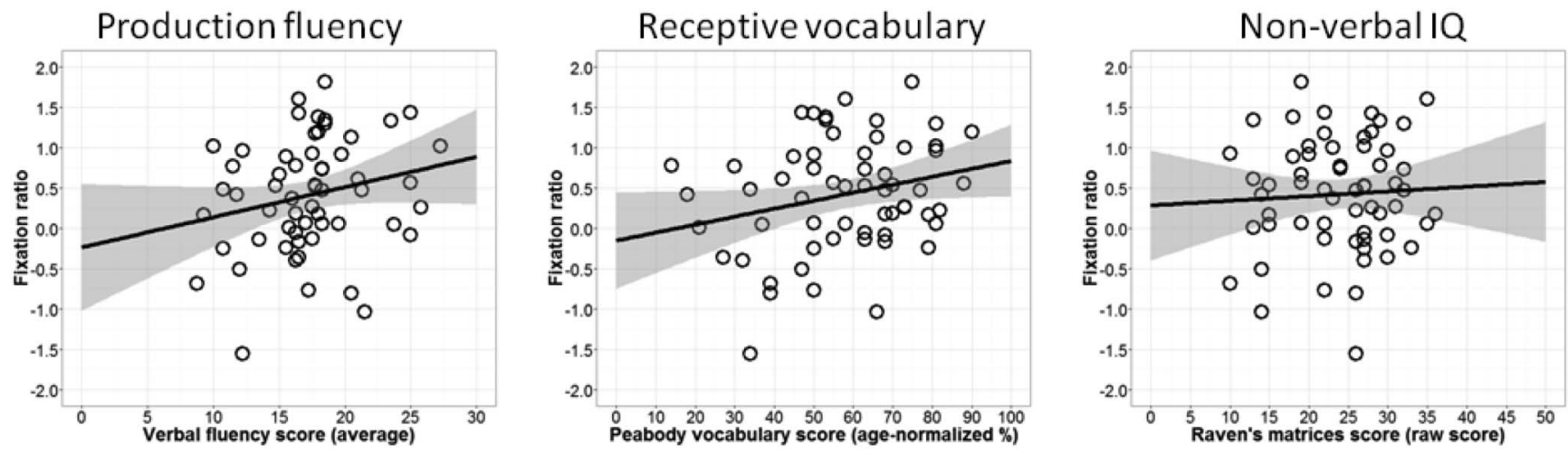

\section{Item correlations}
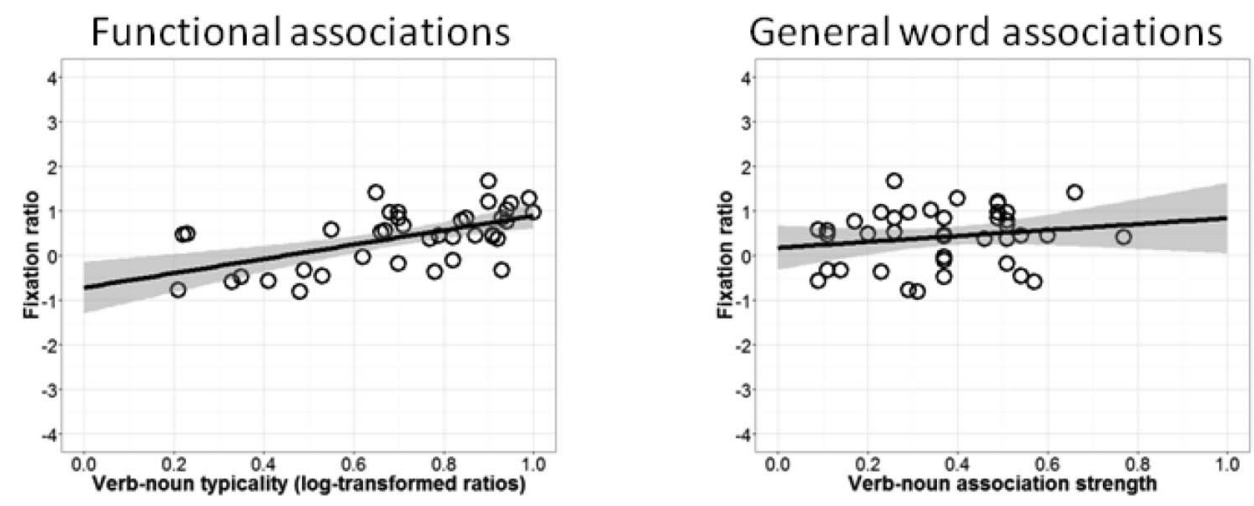

Figure 7. Scatterplots of participant and item correlations for Experiment 2.

To sum up, we found little evidence for a role of general word associations and nonverbal intelligence in predictive language processing. Experiments 1 and 2 support the notion that functional associations, language production abilities, and receptive vocabulary influence verb-mediated anticipatory eye gaze. This finding is consistent with the notion that multiple mechanisms and mediating factors rather than a single mechanism underlie prediction in language processing (Huettig, 2015; Mani \& Huettig, 2013).

What determines the weighting of these multiple mechanisms and mediating factors in predictive language processing? One possibility is that the situational context in which anticipatory language processing occurs determines how strongly each of these factors contributes to prediction (Huettig, 2015). Experiments 1 and 2 suggest that in situations with extensive visual input, functional associations, language production abilities and receptive vocabulary are all related to anticipatory eye gaze. However, even when we talk about things in the 'here and now,' language processing does not always take place with such extensive input from the visual environment (cf. Coco et al., 2016; Ferreira et al., 2013). In many situations visual input is much more limited or even absent. In Experiment 3, we therefore explored the contributions of the same five predictor variables to anticipatory eye gaze when participants had only very limited visual input.

To that end, we conducted the same eye-tracking experiment as before but reduced the amount of visual input participants received by presenting the visual display only $500 \mathrm{~ms}$ prior to the target word onset. Rommers et al. (2013) have recently shown that presenting displays $500 \mathrm{~ms}$ prior to the target word onsets is sufficient time to observe anticipatory eye movements. Experiment 3 was run in one testing session. Participants carried out the eye-tracking experiment, which was followed by the Peabody vocabulary test, the production fluency task, and Raven's progressive matrices test. The session lasted around $90 \mathrm{~min}$.

\section{Experiment 3}

\section{Method}

Participants. Sixty members (mean age $=22$ years of life, $S D=5$ ) of the participant panel of the MPI for Psycholinguistics, all native speakers of Dutch, were paid for their participation. All participants had normal hearing and normal or corrected-to-normal vision. All participants gave written consent beforehand. None of them had taken part in any of the norming studies or in Experiments 1 or 2 .

Stimuli and procedure. The eye-tracking experiment was the same as in Experiments 1 and 2 except that we timed the presentation of the visual display to $500 \mathrm{~ms}$ prior to the target word onset rather than timing it to one second prior to the occurrence of the verb in the spoken signal. A trial started with the presentation of a 
fixation dot in the center of the screen. After two seconds, the playback of the sentence was initiated and the dot remained visible on the screen until it was replaced with the display featuring the four objects, $500 \mathrm{~ms}$ prior to the spoken target word.

As in Experiments 1 and 2, we administered the verbal fluency task, the Peabody vocabulary test, and Raven's progressive matrices test. Because of task misunderstanding, the verbal fluency data of one participant could not be analyzed.

\section{Results and Discussion}

Figure 8 shows the fixations for the eye-tracking experiment. The plots suggest that participants disengaged their overt attention from the fixation dot between 300 and $200 \mathrm{~ms}$ before the onset of the spoken target. Anticipatory looks to the target objects arose around $100 \mathrm{~ms}$ before target onset.

For the regression analyses (see Table 3 , for a summary), we selected a time window of $500 \mathrm{~ms}$ length, starting $200 \mathrm{~ms}$ after the
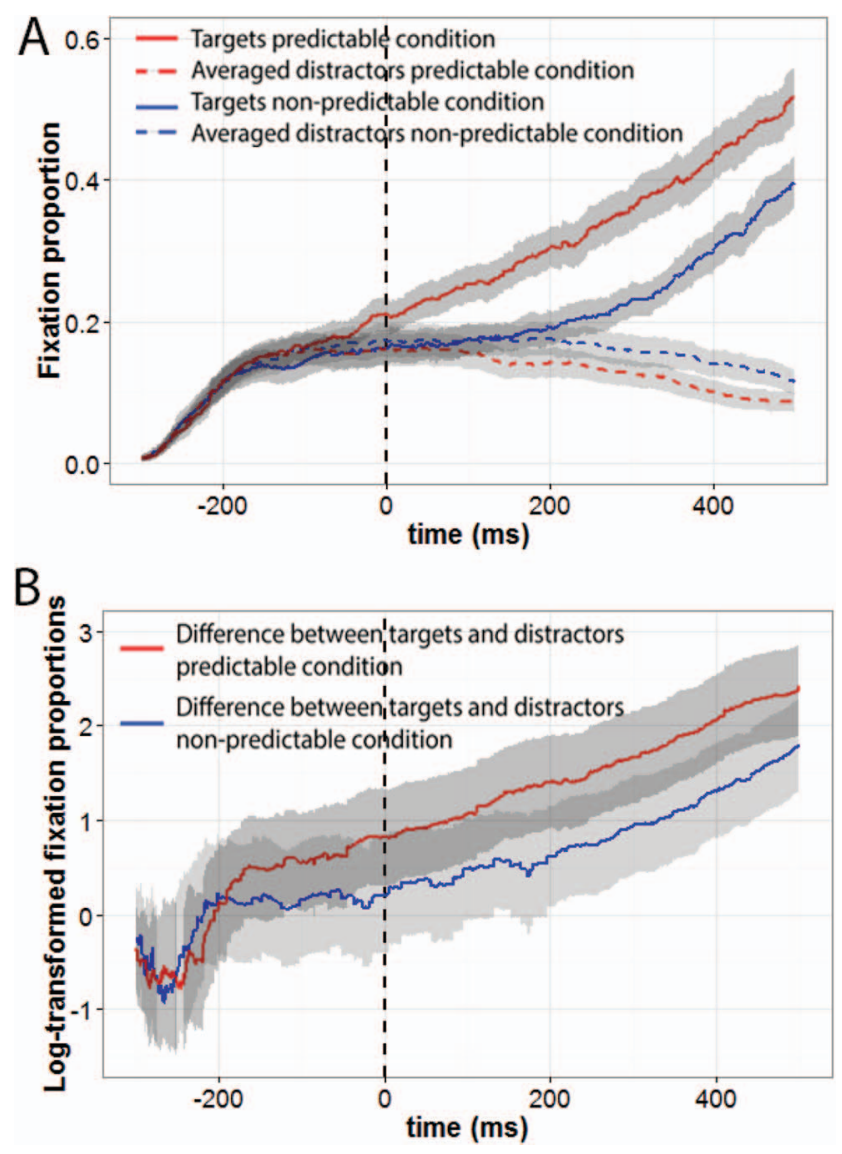

Figure 8. Results of Experiment 3. Panel A plots the fixation proportions for target and averaged distractor objects in the predictable and nonpredictable condition. Panel B plots the difference between log-transformed fixation proportions for target and distractor objects for predictable and nonpredictable conditions. Confidence intervals (95\%), calculated for each sampling step, are shaded in gray. The critical window spanned the time between the presentation of the visual display and the acoustic onset of the target word in the speech signal $(500 \mathrm{~ms})$. Time zero (vertical dashed line) indicates the onset of the target word. See the online article for the color version of this figure. display onset and ending $200 \mathrm{~ms}$ after the spoken target onset, taking into account that it takes approximately $200 \mathrm{~ms}$ to program and initiate a saccadic eye movement (Saslow, 1967). As in the previous experiments we calculated split-half reliability (predictable condition: List $1=.134$, List $2=.309$; nonpredictable condition: List $1=.406$; List $2=.246$ ). Figure 9 shows within participant and between-participants variation in predictive eye gaze during the critical time period (overall mean predictable condition $=.04[S D=.34]$; overall mean nonpredictable condition $=-.003[S D=.31])$.

By-participant regression analysis. As in the previous experiments, the model $\left(R^{2}=.101\right)$ revealed some evidence for the influence of participants' Peabody vocabulary scores on the likelihood of their anticipatory eye movements (unstandardized $\beta=$ $.006, S E \beta=.003$, CI $[.0, .013]$; standardized $\beta=.277, c t=.782$ ) suggesting that participants with larger receptive vocabulary fixated the predictable target longer than participants with smaller receptive vocabulary. As in Experiment 2, we found that Raven's progressive matrices contributed little unique variance to verbmediated anticipatory eye movements (unstandardized $\beta=.007$, $S E \beta=.011$, CI $[-.015, .029]$; standardized $\beta=.092, c t=.812)$. Interestingly, unlike in Experiment 1 and 2, production fluency did not explain much unique variance in anticipatory eye gaze (unstandardized $\beta=-.011$, SE $\beta=.024$, CI [ $-.059, .037]$; standardized $\beta=-.063, c t=.939$, Figure 10 , for scatter plots).

A linear mixed-effects model analysis, identical to that in Experiment 1 , on participants' gaze in the predictable and nonpredictable conditions revealed the following effects: Condition $\beta=$ $.42, S E \beta=.1, t=4.012$, Verbal Fluency $\times$ Condition $\beta=.03$, $S E \beta=.11, t=.309$, Peabody $\times$ Condition $\beta=.21, S E \beta=.11$, $t=1.95$, Raven's $\times$ Condition $\beta=-.14$, SE $\beta=.12, t=-1.164$.

By-item regression analysis. Because we presented the visual objects $500 \mathrm{~ms}$ prior to the onset of the spoken target, that is, after participants had already processed the verb in the spoken sentences, object/noun-verb priming seems very unlikely. Therefore, the by-item regression analysis $\left(R^{2}=.236\right)$ was based on the measures of functional associations and general verb-noun associations. As in the previous two experiments, the results revealed that functional associations were a robust predictor of the likelihood of predictive looks made to an item (unstandardized $\beta=$ 3.808, $S E \beta=1.15$, CI [1.477, 6.139]; standardized $\beta=.491, c t=$ .938). As in the previous experiments, general verb-noun associations were not a strong predictor of the likelihood of predictive looks made to an item (unstandardized $\beta=-.265, S E \beta=1.522$, CI $[-3.350,2.819]$; standardized $\beta=-.026 c t=.938$ ).

In sum, the results of Experiment 3 suggest that although the contributions of receptive vocabulary functional and general associations were similar to those in Experiments 1 and 2, the shortened preview phase affected the contribution of production fluency to predictive eye gaze. With only limited time to preview the four objects, production abilities appear to be less relevant for the deployment of verb-mediated anticipatory eye movements than with an extended preview phase. Unlike in Experiment 1, but similar to Experiment 2, the influence of participants' nonverbal intelligence on predictive language processing was rather weak in Experiment 3.

Joint analysis of Experiments 1, 2, and 3. To facilitate comparison of the results of all experiments, we conducted a supplementary analysis, fitting a linear mixed-effects model on all 

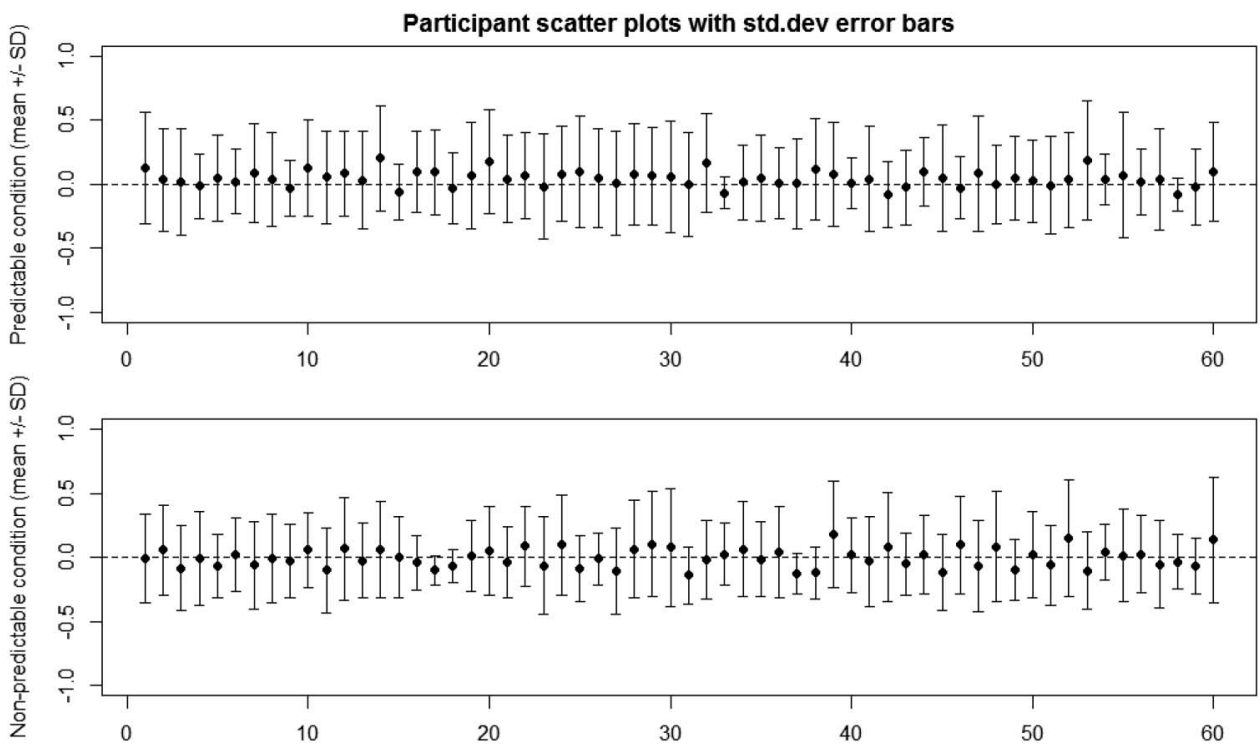

Figure 9. Within-participant and between-participants variation in fixation behavior in Experiment 3. The plots show each participant's mean difference (and standard deviation error bars) between looks to the target and looks to the averaged distractors in the predictable and nonpredictable conditions during the critical time window. A mean difference of zero means equal looks to target and distractors; a positive mean difference implies a bias for the target.

predictable trials of Experiments 1,2, and 3. This analysis enabled us to estimate how each of the predictors that substantially contributed to explaining variance in participants' predictive eye gaze varied across the experiments. It also allowed the simultaneous inclusion of participants and items as random factors, and the simultaneous inclusion of participant and item variables. As in the previous analyses, the dependent variable was log-transformed ratios between looks to the target and looks to the averaged distractors. We included Experiment as a fixed factor with three levels (Experiment 1, Experiment 2, Experiment 3). Participants' verbal fluency scores and their Peabody vocabulary scores, as well as the verb-noun typicality ratings were included as continuous predictors (scaled and centered). The participant regression analysis in Experiment 3 indicated a considerable difference between the unique amount of variance explained by participant's verbal fluency scores in Experiment 3 compared with Experiments 1 and 2. For that reason, the interaction between verbal fluency and Experiment was included. Finally, random intercepts by participants and items, as well as random slopes for verb-noun typicality by participants and random slopes for verbal fluency and Peabody scores by items were added. ${ }^{4}$ Experiment 1 was put on the intercept. The model revealed the following predictor contributions: verbal fluency, $\beta=.202, S E \beta=.085, t=2.382$, Peabody vocabulary, $\beta=.174, S E \beta=.049, t=3.552$, verb-noun typicality, $\beta=.51, S E \beta=.097, t=5.21$. The model further showed that the degree of prediction differed between Experiment 1 and 3 $(\beta=-1.139, S E \beta=.116, t=-9.826)$ but not between Experiment 1 and $2(\beta=-.06, S E \beta=.115, t=-.528)$. Crucially, as implied by the participant regression in Experiment 3, the analysis revealed that the contribution of participants' verbal fluency to explaining variance within predictive gaze was greatly reduced in Experiment 3, but comparable between Experiment 1 and 2 (Ex- periment 1 and 3: Verbal Fluency $\times$ Experiment, $\beta=-.258$, $S E \beta=.132, t=-1.959$; Experiment 1 and 2: Verbal Fluency $\times$ Experiment, $\beta=-.091, S E \beta=.108, t=-.841$ ).

\section{General Discussion}

In the current study, we aimed to determine the influence of five potential predictors of verb-mediated anticipatory eye gaze behavior: functional associations, general word associations, production fluency, receptive vocabulary, and nonverbal intelligence. In three visual world eye-tracking experiments participants looked at visual displays of four objects while listening to sentences in which the target object was predictable ("The man peels the apple") or not predictable ("The man draws the apple"). In Experiments 1 and 2 the visual display was presented one second before the verb was heard. In Experiment 3 participants were given only a short preview of the display starting $500 \mathrm{~ms}$ before the target noun was heard. The predictable sentences varied in verb-noun typicality and general verb-noun association strength, representing measures of functional associations and general word associations, respectively. Participants' production fluency was assessed using the verbal fluency task. We used the Peabody vocabulary test to measure participants' receptive vocabulary and Raven's progressive matrices as a proxy for nonverbal intelligence.

In all three experiments, we found that participants anticipated the predictable spoken targets as indexed by looks to the target objects before they were referred to in the speech signal. No such anticipatory eye movements were observed when the

\footnotetext{
${ }^{4}$ Attempting to fit a more complex model structure (e.g., adding random slopes for Experiment) was not successful as the structure turned out to be too complex and the model(s) did not converge.
} 


\section{Participant correlations}
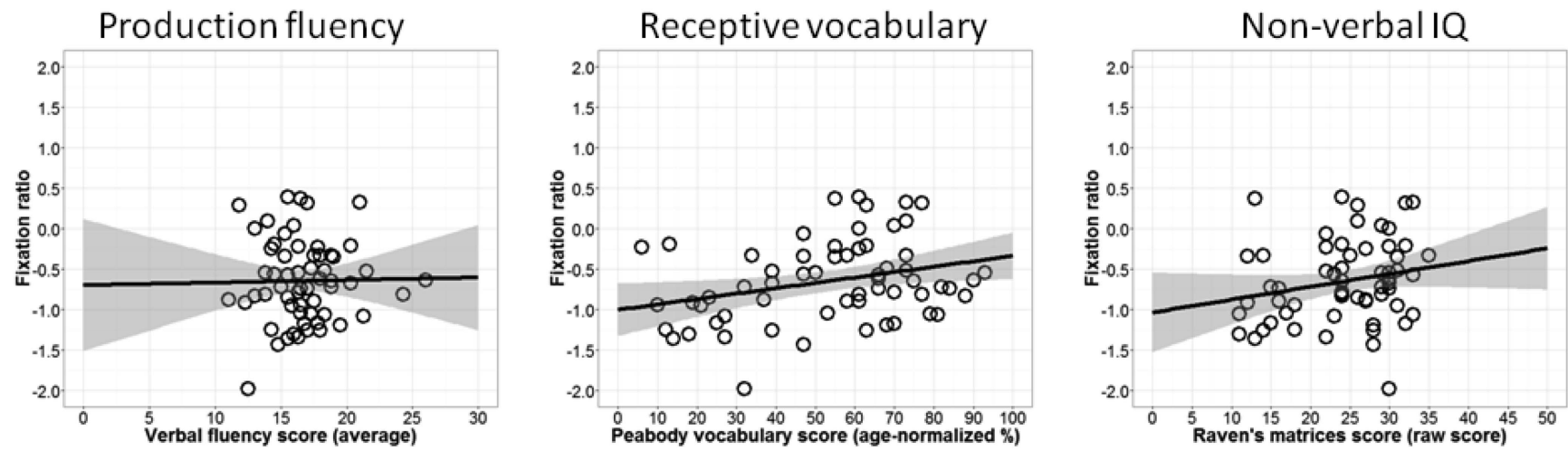

Item correlations
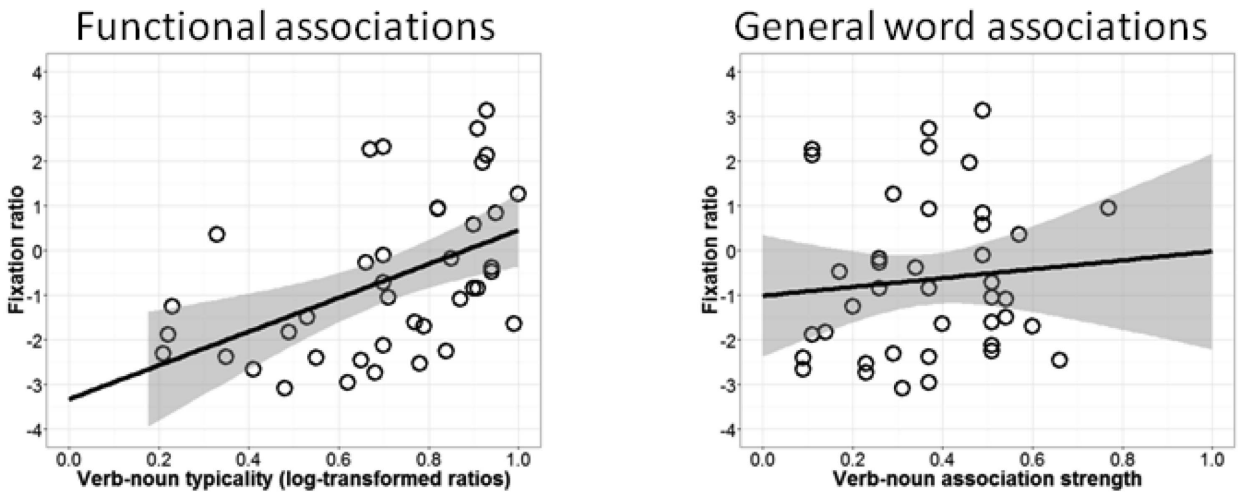

Figure 10. Scatter plots showing participant and item correlations for Experiment 3.

same objects were referred to in nonpredictable sentences. This pattern replicates earlier research (Altmann \& Kamide, 1999). We performed standard multiple regression analyses in which all predictor variables were entered simultaneously into the regression equation to estimate the unique contributions of each predictor variable.

By-item regression revealed that functional associations were the most robust predictor of verb-mediated anticipatory eye movements in all three experiments. This conclusion is based on a positive relationship between the likelihood of anticipatory looks made to an item and that item's verb-noun typicality rating. In contrast, there was little evidence pointing toward a contribution of general word associations to verb-mediated anticipatory eye movements.

By-participant regression, with three individual differences measures thought to tap production fluency, receptive vocabulary, and nonverbal intelligence, revealed receptive vocabulary to be a robust predictor of verb-mediated anticipatory eye movements in all three experiments. Production fluency correlated positively with the likelihood of anticipator eye movements (and explained substantial unique variance) when participants were given the long preview but not when given the short preview of the visual display. We will now discuss the implications of each of these findings.

\section{Functional Versus General Word Associations}

Our findings of a robust role of functional associations for language-mediated anticipatory eye gaze are compatible with the findings of Kukona et al. (2011). Their results can be interpreted as showing that on processing a transitive verb such as "arrest" functionally associated concepts are preactivated irrespective of their thematic fit in the local sentence context. The present results are also in line with the developmental findings of Borovsky et al. (2014). These authors reported evidence for the involvement of associations in anticipatory language processing in 3- to 4-yearolds. Given that the children in their study were instructed to learn connections between agents, actions, and objects, anticipatory eye movements in that study were most likely also driven by functional rather than general associations. The present results show that functional associations are a strong predictor of verb-mediated anticipatory eye gaze in adults. More generally, our results provide further support for the notion that functional knowledge is a particularly salient aspect of word meaning (e.g., Moss et al., 1997).

The lack of an effect of general associations may be surprising given its assumed important role in cognitive processing (see Hutchison, 2003, for a review) and specifically in prediction (Bar, 2007, 2009). Using nonpredictable sentences such as "Eventually 
she looked at the beaker that was in front of her" and displays of four visual objects, Huettig and McQueen (2007) found that participants first looked at phonological (beaver) and then at semantic (fork) and visual (bobbin) competitors during the unfolding of the target "beaker." This implies the activation of knowledge on multiple levels of representation during spoken word processing (see Smith, Monaghan, \& Huettig, 2017, for computational modeling evidence). One might expect that general associations, a measure sensitive to the sum of multiple associative connections between a cue and a target should capture predictive gaze more precisely than a component of that sum (e.g., functional associations). We suggest that the situation in which language processing takes place affects the impact of particular types of associations: In the current experiments functional associations were more important than general associations. It is likely that functional associations between verbs and nouns (and not general associative strength) predicted anticipatory eye movements so well because of the presence of the objects. That is, the presence of the target referents may have boosted the preactivation of functional associations to the verbs. Seeing something that has the visual shape listeners would typically associate with 'peelable' objects (even for only a short period of time, Experiment 3) might increase the likelihood of fixations to an apple (cf. Hintz, Meyer, \& Huettig, submitted, on the influence of visual preview on subsequent anticipatory language processing).

On the other hand, it is also possible that general associations play only a weak role in predictive language processing overall. Some hints in this regard come from eye-tracking research on reading. McDonald and Shillcock (2003) assembled a corpus of contemporary English (i.e., 10 newspaper articles), which they asked participants to read. They found that transitional probability, the probability of transitioning from one word into another, influenced fixation durations during reading. Transitional probability, which corresponds to the frequency of co-occurrence of two words, is conceptually similar to general associations. The authors' finding is thus in line with the notion that general associations are important for prediction during reading. However, Frisson, Rayner, and Pickering (2005) replicated the findings of McDonald and Shillcock (2003) in one experiment, but not in a second experiment where items were matched for Cloze values, a measure typically assumed to reflect the overall predictability of a word (Taylor, 1953). Frisson and colleagues concluded that low level transitional probabilities do not explain prediction above predictability effects determined by the use of a cloze task. Future research is required on the role of general word associations in prediction in language processing.

\section{Production Ability}

Although it is likely that functional associations are particularly important in situations of language processing with visual context copresent, the results of the regression analyses in all three experiments support the view that functional associations predict verbmediated anticipatory eye movements in both scenarios tested in the current study (long and short visual preview). In contrast, participants' production fluency correlated positively with their likelihood of anticipatory eye movements in the long, but not in the short preview condition. Even though the effect size for the influence of production fluency in Experiment 2 was weaker than in Experiment 1 (standard- ized $\beta=.194$ vs. standardized $\beta=.269$ ), both differed substantially from the results obtained with the short preview manipulation (Experiment 3; standardized $\beta=-.063$ ). Thus, a sufficient preview period seems to play a pivotal role for the engagement of productionbased prediction. The pattern suggests, more generally, that the influence of mechanisms also involved in preparing to speak may be particularly potent in situations in which language users can sufficiently exploit the visual input.

Note that the developmental study by Mani and Huettig (2012) and the adult study by Rommers et al. (2015), who also obtained evidence for production-based prediction, used spoken sentences and pictures as well. In the experiments by Federmeier and colleagues (2002, 2010), correlations between prediction-related ERP components and students' and older participants' production fluency scores were found although the experiments did not feature any pictorial input. This suggests that production abilities can modulate predictive language processing in multiple situations (e.g., reading, language-vision mapping). We suggest, however, that the likelihood of the involvement of production-based mechanisms in prediction may increase with relevant visual context present. $^{5}$

Why might this be the case? Imagine, for instance, two persons talking to each other face-to-face. They share the same visual environment and hence have a common nonlinguistic source of information available to facilitate the prediction of upcoming language, for example when the speaker refers to objects in the visual environment. In such situations, comprehenders might be inclined to engage in the question "How would I finish the sentence if I was the speaker, given the visual objects surrounding me?." In contrast to such a scenario, try to think of a telephone call between the same persons. We conjecture that in situations with limited relevant visual input (as in Experiment 3), comprehenders are less likely to employ production-based mechanisms for prediction.

There are three arguments about the current data that suggest that the verbal fluency task measures at least partly production abilities rather than general cognitive abilities. First, verbal fluency scores and general intelligence scores (e.g., nonverbal intelligence; as measured using Raven's progressive matrices) did not correlate strongly in any of the three experiments. This also hints at the second argument: In the past, performance on verbal fluency tasks has been linked to general processing speed (e.g., Bryan, Luszcz, \& Crawford, 1997). One might hence argue that general cognitive processing speed rather than production fluency was crucial in the current set of experiments. That is, those participants who could process visual input more rapidly and link it to the unfolding language were the ones who

\footnotetext{
${ }^{5}$ Converging experimental evidence for this claim comes from another study conducted in our lab. As described above, Rommers et al. (2015) reported a positive correlation between Dutch participants' degree of prediction (given a long preview of the visual scene) and their verbal fluency scores $(r=.23, n=81)$. However, the same experiment conducted with a short preview phase of only $500 \mathrm{~ms}$ prior to the spoken targets (Rommers et al., 2013) yielded a greatly reduced correlation (time window: $100 \mathrm{~ms}$ preceding target word onset; $r=-.1, n=45$; Rommers, personal communication).This demonstrates that even with predictable sentences that were semantically and syntactically more variable (e.g., "In 1961, Neil Armstrong was the first man to set foot on the moon") than the sentences in the present study, the contribution of production fluency to explaining variance in predictive gaze was absent with reduced visual input. This renders the possibility unlikely that the observed differences between the present Experiment 1 (and 2) and the present Experiment 3 were a sheer spurious finding.
} 
predicted earlier. In that case the correlation between participants' predictive gaze and their verbal fluency scores should have been particularly evident in even more challenging situations of visual processing such as in Experiment 3. Finally, there was no substantial correlation in any of the experiments between participants' vocabulary knowledge as measured using the Peabody vocabulary test and their verbal fluency scores. This suggests that, at least in our study, the verbal fluency task was not simply tapping vocabulary knowledge. Therefore, we believe that our results point to the possibility that production-based mechanisms might indeed be involved in anticipatory language processing. In Experiments 1 and 2, with longer previews of the visual scene, the pictures may have served as lexical retrieval cues just as the categories and letters served as lexical retrieval cues in the verbal fluency task. Participants who were able to quickly retrieve lexical items after being cued in the verbal fluency task may have profited more from the picture input in the eye-tracking experiment and used those to make predictions about potentially upcoming words. Clearly, more research is needed to examine the involvement of production-based mechanisms in prediction. However, our results add to a growing body of correlational evidence suggesting a modulating influence of production abilities on anticipatory language processing.

\section{Receptive Vocabulary Knowledge}

Our findings provide further evidence for a link between receptive vocabulary knowledge and anticipatory spoken language processing, replicating previous results in children (Borovsky et al., 2012) and student populations (Rommers et al., 2015). It is worth noting again that receptive vocabulary robustly accounted for unique variance of verb-mediated anticipatory eye gaze beyond production fluency.

Some researchers have argued that receptive vocabulary knowledge may be a good proxy for literacy (cf. Nation \& Cocksey, 2009). In line with that notion, recent studies have reported results showing a meditating influence of literacy on predictive language processing. For example, Mishra et al. (2012) conducted a visual world prediction study with persons with low and higher degrees of literacy in India. They found that the time course of the gazes to the targets differed: High literates started to look more at the target object than at unrelated distractors immediately upon hearing a semantically and syntactically biasing adjective. By contrast, the eye gaze of low literates to the targets only started to differ from looks to the unrelated distractors once the spoken target word acoustically unfolded. Mishra et al. concluded that low literates did not use the information from the unfolding spoken words to predict upcoming referents. Moreover, Huettig and Brouwer (2015) found further evidence for an effect of literacy on anticipatory eye gaze. They tested Dutch adults with dyslexia and a control group of adults without a history of reading disorders. Adults with dyslexia anticipated target objects in the visual world study later than controls. Similarly, James and Watson (2013) showed that literacy (as measured in the Comparative Reading Habits Questionnaire, Acheson, Wells, \& MacDonald, 2008, and the American Adult Reading Test, Blair \& Spreen, 1989) was linked to anticipatory language-mediated eye movements among American college students.

Mani and Huettig (2014) proposed that enhanced literacy may exert its influence on predictive language processing by sharpening orthographic representations and lexical representations more generally, such that information may be available more quickly during online speech processing. On such an account, variation in receptive vocabulary size may reflect differences in the ability to perceive the form of a word and retrieve its meaning. For example, one could speculate that increased reading exposure leads to familiarity with a larger number of words and speeded lexical access. Further research is needed to test this proposal.

\section{Nonverbal Intelligence}

Finally, our results show that nonverbal intelligence accounts only for little unique variance in verb-mediated anticipatory eye movements. This is consistent with the notion that linguistic anticipation abilities are largely independent of nonverbal abilities (see Rommers et al., 2015, for some evidence that verbal and nonverbal anticipation abilities may be distinct).

\section{A Pluralistic Approach to Predictive Language Processing}

Taken together the results suggest that language users do not rely on a single mechanism to predict upcoming language. Instead, prediction in language processing is driven by several mechanisms and influenced by various mediating factors. Specifically, prediction is influenced by both properties of the incoming linguistic stimulus and by characteristics of the listeners.

The possibility that multiple mechanisms underlie predictive language processing has recently been suggested by several researchers (Kuperberg, 2007; Huettig, 2015; Mani \& Huettig, 2013; Pickering \& Garrod, 2013; Wlotko \& Federmeier, 2013). Pickering and Garrod (2013) for instance assume that "comprehenders will emphasize [production-based mechanisms] when they are (or appear to be) similar to the speaker" and that "[associations are] more accurate for simple, "one-step" associations between a current and a subsequent state" (p. 346). They also point out that comprehenders may combine both mechanisms. Our results are consistent with this view. However, our results also signal the need for adjustments to Pickering and Garrod's account and other theories of predictive language processing. The situational context, in the present case the amount of visual preview, seems to be crucial in determining the contribution of each of the underlying mechanisms. In line with such a notion, previous research has demonstrated that the presence of a relevant visual context can exert a substantial influence on subsequent language processing (e.g., Coco et al., 2016; Ferreira et al., 2013). Future research could examine how exactly the visual and the language systems interact to further illuminate how visual context might constrain anticipatory language processing.

\section{Conclusion}

A main goal of readers and listeners is to understand the communicated content as fast as possible. Prediction might be a tool used to achieve that. The present research highlights that multiple mechanisms are involved in generating predictions, and that their impact may depend at least partly on the available input sources. Spoken language processing often occurs in the context of visual information that may be relevant for generating predictions. Hence, it is not surprising that the presence or absence of visual input affects which mechanism contributes to prediction. An im- 
portant goal for further research is to determine which factors determine the relative impact of the mechanisms underlying predictive language processing.

\section{References}

Acheson, D. J., Wells, J. B., \& MacDonald, M. C. (2008). New and updated tests of print exposure and reading abilities in college students. Behavior Research Methods, 40, 278-289. http://dx.doi.org/10.3758/ BRM.40.1.278

Abwender, D. A., Swan, J. G., Bowerman, J. T., \& Connolly, S. W. (2001). Qualitative analysis of verbal fluency output: Review and comparison of several scoring methods. Assessment, 8, 323-338. http://dx.doi.org/10 $.1177 / 107319110100800308$

Altmann, G. T. M., \& Kamide, Y. (1999). Incremental interpretation at verbs: Restricting the domain of subsequent reference. Cognition, 73, 247-264. http://dx.doi.org/10.1016/S0010-0277(99)00059-1

Altmann, G. T. M., \& Mirković, J. (2009). Incrementality and prediction in human sentence processing. Cognitive Science, 33, 583-609. http://dx .doi.org/10.1111/j.1551-6709.2009.01022.x

Amato, M. S., \& MacDonald, M. C. (2010). Sentence processing in an artificial language: Learning and using combinatorial constraints. Cognition, 116, 143-148.

Arai, M., \& Keller, F. (2013). The use of verb-specific information for prediction in sentence processing. Language and Cognitive Processes, 28, 525-560. http://dx.doi.org/10.1080/01690965.2012.658072

Arai, M., van Gompel, R. P., \& Scheepers, C. (2007). Priming ditransitive structures in comprehension. Cognitive Psychology, 54, 218-250. http:// dx.doi.org/10.1016/j.cogpsych.2006.07.001

Baayen, R. H., Piepenbrock, R., \& Gulikers, L. (1993). The CELEX lexical database on CD-ROM. Philadelphia, PA: University of Pennsylvania. [Distributor]

Bar, M. (2007). The proactive brain: Using analogies and associations to generate predictions. Trends in Cognitive Sciences, 11, 280-289. http:// dx.doi.org/10.1016/j.tics.2007.05.005

Bar, M. (2009). The proactive brain: Memory for predictions. Philosophical Transactions of the Royal Society of London Series B, Biological Sciences, 364, 1235-1243. http://dx.doi.org/10.1098/rstb.2008.0310

Bates, D., Mächler, M., Bolker, B., \& Walker, S. (2015). Fitting linear mixed-effects models using 1me4. Journal of Statistical Software, 67, 48.

Blair, J. R., \& Spreen, O. (1989). Predicting premorbid IQ: A revision of the National Adult Reading Test. Clinical Neuropsychologist, 3, 129136. http://dx.doi.org/10.1080/13854048908403285

Boersma, P. P. G. (2002). Praat, a system for doing phonetics by computer (Version 5.1.19) [Computer program]. Available from http://www.praat .org/.

Borovsky, A., Elman, J. L., \& Fernald, A. (2012). Knowing a lot for one's age: Vocabulary skill and not age is associated with anticipatory incremental sentence interpretation in children and adults. Journal of Experimental Child Psychology, 112, 417-436. http://dx.doi.org/10.1016/j .jecp.2012.01.005

Borovsky, A., Sweeney, K., Elman, J. L., \& Fernald, A. (2014). Real-time interpretation of novel events across childhood. Journal of Memory and Language, 73, 1-14. http://dx.doi.org/10.1016/j.jml.2014.02.001

Bryan, J., Luszcz, M. A., \& Crawford, J. R. (1997). Verbal knowledge and speed of information processing as mediators of age differences in verbal fluency performance among older adults. Psychology and Aging, 12, 473.

Chang, F., Dell, G. S., \& Bock, K. (2006). Becoming syntactic. Psychological Review, 113, 234-272. http://dx.doi.org/10.1037/0033-295X .113.2.234

Chen, E., Gibson, E., \& Wolf, F. (2005). Online syntactic storage costs in sentence comprehension. Journal of Memory and Language, 52, 144 169. http://dx.doi.org/10.1016/j.jml.2004.10.001
Chomsky, N. (2014). Aspects of the theory of syntax (Vol. 11). Cambridge, MA: MIT press.

Clark, A. (2013). Whatever next? Predictive brains, situated agents, and the future of cognitive science. Behavioral and Brain Sciences, 36, 181204. http://dx.doi.org/10.1017/S0140525X12000477

Coco, M. I., Keller, F., \& Malcolm, G. L. (2016). Anticipation in realworld scenes: The role of visual context and visual memory. Cognitive Science, 40, 1995-2024.

Cumming, G. (2012). Understanding the new statistics: Effect sizes, confidence intervals, and meta-analysis. New York, NY: Routledge.

Cumming, G. (2014). The new statistics: Why and how. Psychological Science, 25, 7-29. http://dx.doi.org/10.1177/0956797613504966

Deary, I. J. (2001). Human intelligence differences: A recent history. Trends in Cognitive Sciences, 5, 127-130. http://dx.doi.org/10.1016/ S1364-6613(00)01621-1

de Deyne, S., Navarro, D. J., \& Storms, G. (2013). Better explanations of lexical and semantic cognition using networks derived from continued rather than single-word associations. Behavior Research Methods, 45, 480-498.

Dell, G. S., \& Chang, F. (2013). The P-chain: Relating sentence production and its disorders to comprehension and acquisition. Philosophical Transactions of the Royal Society of London: Series B, Biological Sciences, 369, 20120394. http://dx.doi.org/10.1098/rstb.2012.0394

DeLong, K. A., Urbach, T. P., \& Kutas, M. (2005). Probabilistic word pre-activation during language comprehension inferred from electrical brain activity. Nature Neuroscience, 8, 1117-1121. http://dx.doi.org/10 $.1038 / \mathrm{nn} 1504$

Dowty, D. (1991). Thematic proto-roles and argument selection. Language, 67, 547-619. http://dx.doi.org/10.1353/lan.1991.0021

Duñabeitia, J. A., Avilés, A., Afonso, O., Scheepers, C., \& Carreiras, M. (2009). Qualitative differences in the representation of abstract versus concrete words: Evidence from the visual-world paradigm. Cognition, 110, 284-292. http://dx.doi.org/10.1016/j.cognition.2008.11.012

Dunn, D. M., \& Dunn, L. M. (2007). Peabody picture vocabulary test: Manual. Upper Saddle River, NJ: Pearson.

Dunn, L. M., \& Dunn, D. (1997). Peabody Picture Vocabulary Test (3rd ed.). Circle Pines, MN: American Guidance Service.

Federmeier, K. D. (2007). Thinking ahead: The role and roots of prediction in language comprehension. Psychophysiology, 44, 491-505. http://dx .doi.org/10.1111/j.1469-8986.2007.00531.x

Federmeier, K. D., Kutas, M., \& Schul, R. (2010). Age-related and individual differences in the use of prediction during language comprehension. Brain and Language, 115, 149-161. http://dx.doi.org/10.1016/j .band1.2010.07.006

Federmeier, K. D., McLennan, D. B., De Ochoa, E., \& Kutas, M. (2002). The impact of semantic memory organization and sentence context information on spoken language processing by younger and older adults: An ERP study. Psychophysiology, 39, 133-146. http://dx.doi.org/10 $.1111 / 1469-8986.3920133$

Ferreira, F., Foucart, A., \& Engelhardt, P. E. (2013). Language processing in the visual world: Effects of preview, visual complexity, and prediction. Journal of Memory and Language, 69, 165-182. http://dx.doi.org/ 10.1016/j.jml.2013.06.001

Ferretti, T. R., McRae, K., \& Hatherell, A. (2001). Integrating verbs, situation schemas, and thematic role concepts. Journal of Memory and Language, 44, 516-547. http://dx.doi.org/10.1006/jmla.2000.2728

Fidler, F., \& Loftus, G. R. (2009). Why figures with error bars should replace p-values. Zeitschrift für Psychologie/The Journal of Psychology, 217, 27-37.

Frisson, S., Rayner, K., \& Pickering, M. J. (2005). Effects of contextual predictability and transitional probability on eye movements during reading. Journal of Experimental Psychology: Learning, Memory, and Cognition, 31, 862-877. http://dx.doi.org/10.1037/0278-7393.31.5.862 
Friston, K. (2010). The free-energy principle: A unified brain theory? Nature Reviews Neuroscience, 11, 127-138. http://dx.doi.org/10.1038/ nrn2787

Gennari, S. P., \& MacDonald, M. C. (2009). Linking production and comprehension processes: The case of relative clauses. Cognition, 111, $1-23$.

Gruber, J. S. (1965). Studies in lexical relations. [Unpublished Ph.D. dissertation.]. Cambridge, MA: MIT.

Hintz, F., Meyer, A. S., \& Huettig, F. (2016). Encouraging prediction during production facilitates subsequent comprehension: Evidence from interleaved object naming in sentence context and sentence reading. Quarterly Journal of Experimental Psychology: Human Experimental Psychology, 69, 1056-1063. http://dx.doi.org/10.1080/17470218.2015 .1131309

Hintz, F., Meyer, A. S., Huettig, F. (submitted). I see what you're going to say: Listeners' use of contextual visual information during predictive language processing restricts visual and semantic competition.

Huettig, F. (2015). Four central questions about prediction in language processing. Brain Research, 1626, 118-135. http://dx.doi.org/10.1016/ j.brainres.2015.02.014

Huettig, F., \& Altmann, G. T. M. (2005). Word meaning and the control of eye fixation: Semantic competitor effects and the visual world paradigm. Cognition, 96, B23-B32. http://dx.doi.org/10.1016/j.cognition.2004.10 .003

Huettig, F., \& Altmann, G. T. M. (2007). Visual-shape competition during language-mediated attention is based on lexical input and not modulated by contextual appropriateness. Visual Cognition, 15, 985-1018. http:// dx.doi.org/10.1080/13506280601130875

Huettig, F., \& Brouwer, S. (2015). Delayed anticipatory spoken language processing in adults with dyslexia: Evidence from eye-tracking. Dyslexia: An International Journal of Research and Practice, 21, 97-122. http://dx.doi.org/10.1002/dys.1497

Huettig, F., \& Janse, E. (2016). Individual differences in working memory and processing speed predict anticipatory spoken language processing in the visual world. Language, Cognition and Neuroscience, 31, 80-93. http://dx.doi.org/10.1080/23273798.2015.1047459

Huettig, F., \& McQueen, J. M. (2007). The tug of war between phonological, semantic and shape information in language-mediated visual search. Journal of Memory and Language, 57, 460-482. http://dx.doi .org/10.1016/j.jml.2007.02.001

Huettig, F., Quinlan, P. T., McDonald, S. A., \& Altmann, G. T. M. (2006). Models of high-dimensional semantic space predict language-mediated eye movements in the visual world. Acta Psychologica, 121, 65-80. http://dx.doi.org/10.1016/j.actpsy.2005.06.002

Huettig, F., Rommers, J., \& Meyer, A. S. (2011). Using the visual world paradigm to study language processing: A review and critical evaluation. Acta Psychologica, 137, 151-171. http://dx.doi.org/10.1016/j.actpsy .2010 .11 .003

Hutchison, K. A. (2003). Is semantic priming due to association strength or feature overlap? A microanalytic review. Psychonomic Bulletin \& Review, 10, 785-813. http://dx.doi.org/10.3758/BF03196544

Iordanescu, L., Grabowecky, M., \& Suzuki, S. (2011). Object-based auditory facilitation of visual search for pictures and words with frequent and rare targets. Acta Psychologica, 137, 252-259. http://dx.doi.org/10 .1016/j.actpsy.2010.07.017

Iordanescu, L., Guzman-Martinez, E., Grabowecky, M., \& Suzuki, S. (2008). Characteristic sounds facilitate visual search. Psychonomic Bulletin \& Review, 15, 548-554. http://dx.doi.org/10.3758/PBR.15.3.548

Ito, A., Corley, M., Pickering, M. J., Martin, A. E., \& Nieuwland, M. S. (2016). Predicting form and meaning: Evidence from brain potentials. Journal of Memory and Language, 86, 157-171. http://dx.doi.org/10 .1016/j.jml.2015.10.007

Jackendoff, R. (1987). The status of thematic relations in linguistic theory. Linguistic Inquiry, 18, 369-411.
James, A., \& Watson, D. (2013). Language experience and prediction in auditory sentence comprehension. Paper presented at the 19th Architectures and Mechanisms for Language Processing Conference (AMLaP 2013), Marseille, France.

Kamide, Y. (2008). Anticipatory processes in sentence processing. Language and Linguistics Compass, 2, 647-670. http://dx.doi.org/10.1111/ j.1749-818X.2008.00072.X

Katz, J., \& Fodor, J. (1963). The structure of a semantic theory. Language, 39, 170-210. http://dx.doi.org/10.2307/411200

Keller, F., Gunasekharan, S., Mayo, N., \& Corley, M. (2009). Timing accuracy of Web experiments: A case study using the WebExp software package. Behavior Research Methods, 41, 1-12. http://dx.doi.org/10 .3758/BRM.41.1.12

Keuleers, E., Brysbaert, M., \& New, B. (2010). SUBTLEX-NL: A new measure for Dutch word frequency based on film subtitles. Behavior Research Methods, 42, 643-650. http://dx.doi.org/10.3758/BRM.42.3 .643

Kukona, A., Fang, S. Y., Aicher, K. A., Chen, H., \& Magnuson, J. S. (2011). The time course of anticipatory constraint integration. Cognition, 119, 23-42. http://dx.doi.org/10.1016/j.cognition.2010.12.002

Kuperberg, G. R. (2007). Neural mechanisms of language comprehension: Challenges to syntax. Brain Research, 1146, 23-49. http://dx.doi.org/ 10.1016/j.brainres.2006.12.063

Kutas, M., DeLong, K. A., \& Smith, N. J. (2011). A look around at what lies ahead: Prediction and predictability in language processing. In M. Bar (Ed.), Predictions in the brain: Using our past to predict the future (pp. 190-207). New York, NY: Oxford University Press. http://dx.do .org/10.1093/acprof:oso/9780195395518.003.0065

Laszlo, S., Stites, M., \& Federmeier, K. D. (2012). Won't get fooled again: An event-related potential study of task and repetition effects on the semantic processing of items without semantics. Language and Cognitive Processes, 27, 257-274. http://dx.doi.org/10.1080/01690965.2011 .606667

Luo, L., Luk, G., \& Bialystok, E. (2010). Effect of language proficiency and executive control on verbal fluency performance in bilinguals Cognition, 114, 29-41. http://dx.doi.org/10.1016/j.cognition.2009.08 .014

Macmillan, N. A., \& Creelman, C. D. (1991). Detection theory: A user's guide. New York, NY: Cambridge University Press.

Mani, N., \& Huettig, F. (2012). Prediction during language processing is a piece of cake-But only for skilled producers. Journal of Experimental Psychology: Human Perception and Performance, 38, 843-847. http:// dx.doi.org/10.1037/a0029284

Mani, N., \& Huettig, F. (2013). Towards a complete multiple-mechanism account of predictive language processing. Behavioral and Brain Sciences, 36, 365-366. http://dx.doi.org/10.1017/S0140525X12002646

Mani, N., \& Huettig, F. (2014). Word reading skill predicts anticipation of upcoming spoken language input: A study of children developing proficiency in reading. Journal of Experimental Child Psychology, 126, 264-279. http://dx.doi.org/10.1016/j.jecp.2014.05.004

McDonald, S. A., \& Shillcock, R. C. (2003). Low-level predictive inference in reading: The influence of transitional probabilities on eye movements. Vision Research, 43, 1735-1751. http://dx.doi.org/10.1016/ S0042-6989(03)00237-2

McQueen, J. M., \& Huettig, F. (2014). Interference of spoken word recognition through phonological priming from visual objects and printed words. Attention, Perception, \& Psychophysics, 76, 190-200. http://dx.doi.org/10.3758/s13414-013-0560-8

McRae, K., Ferretti, T. R., \& Amyote, L. (1997). Thematic roles as verb-specific concepts. Language and Cognitive Processes, 12, 137176. http://dx.doi.org/10.1080/016909697386835

McRae, K., Hare, M., Elman, J. L., \& Ferretti, T. (2005). A basis for generating expectancies for verbs from nouns. Memory \& Cognition, 33, 1174-1184. http://dx.doi.org/10.3758/BF03193221 
Mishra, R. K., Singh, N., Pandey, A., \& Huettig, F. (2012). Spoken language-mediated anticipatory eye-movements are modulated by reading ability - Evidence from Indian low and high literates. Journal of Eye Movement Research, 5, 1-10.

Moss, H. E., McCormick, S., \& Tyler, L. K. (1997). The time course of activation of semantic information during spoken word recognition. Language and Cognitive Processes, 12, 695-732. http://dx.doi.org/10 .1080/016909697386664

Moss, H. E., Ostrin, R. K., Tyler, L. K., \& Marslen-Wilson, W. D. (1995). Accessing different types of lexical semantic information: Evidence from priming. Journal of Experimental Psychology: Learning, Memory, andCcognition, 21, 863.

Nation, K., \& Cocksey, J. (2009). The relationship between knowing a word and reading it aloud in children's word reading development. Journal of Experimental Child Psychology, 103, 296-308. http://dx.doi .org/10.1016/j.jecp.2009.03.004

Neely, J. H. (1991). Semantic priming effects in visual word recognition: A selective review of current findings and theories. Basic processes in reading: Visual word recognition, 11, 264-336.

Nelson, D. L., McEvoy, C. L., \& Schreiber, T. A. (2004). The University of South Florida free association, rhyme, and word fragment norms. Behavior Research Methods, Instruments \& Computers, 36, 402-407. http://dx.doi.org/10.3758/BF03195588

Pickering, M. J., \& Garrod, S. (2007). Do people use language production to make predictions during comprehension? Trends in Cognitive Sciences, 11, 105-110. http://dx.doi.org/10.1016/j.tics.2006.12.002

Pickering, M. J., \& Garrod, S. (2013). An integrated theory of language production and comprehension. Behavioral and Brain Sciences, 36, 329-347. http://dx.doi.org/10.1017/S0140525X12001495

Raven, J. (2000). The Raven's progressive matrices: Change and stability over culture and time. Cognitive Psychology, 41, 1-48. http://dx.doi.org/ 10.1006/cogp.1999.0735

Raven, J., Raven, J. C., \& Court, J. H. (1998). Raven manual section 4: Advanced progressive matrices. Oxford, UK: Oxford Psychologists Press

R Development Core Team. (2012). R: A language and environment for statistical computing. Vienna, Austria: R Foundation for Statistical Computing. Open access available at: http://cran.rproject.org

Rommers, J., Meyer, A. S., \& Huettig, F. (2015). Verbal and nonverbal predictors of language-mediated anticipatory eye movements. Attention, Perception, \& Psychophysics, 77, 720-730. http://dx.doi.org/10.3758/ s13414-015-0873-x

Rommers, J., Meyer, A. S., Praamstra, P., \& Huettig, F. (2013). The contents of predictions in sentence comprehension: Activation of the shape of objects before they are referred to. Neuropsychologia, 51, 437-447. http://dx.doi.org/10.1016/j.neuropsychologia.2012.12.002

Saslow, M. G. (1967). Latency for saccadic eye movement. Journal of the Optical Society of America, 57, 1030-1033. http://dx.doi.org/10.1364/ JOSA.57.001030

Schiller, N. O., Horemans, I., Ganushchak, L., \& Koester, D. (2009). Event-related brain potentials during the monitoring of speech errors. NeuroImage, 44, 520-530. http://dx.doi.org/10.1016/j.neuroimage.2008 .09 .019

Schlichting, L. (2005). Peabody Picture Vocabulary Test Dutch-III-NL. Amsterdam, NL: Harcourt Assessment BV.

Shao, Z., Janse, E., Visser, K., \& Meyer, A. S. (2014). What do verbal fluency tasks measure? Predictors of verbal fluency performance in older adults. Frontiers in Psychology, 5, 772. http://dx.doi.org/10.3389/ fpsyg.2014.00772

Shelton, J. R., \& Martin, R. C. (1992). How semantic is automatic semantic priming? Journal of Experimental Psychology: Learning, Memory, and Cognition, 18, 1191-1210. http://dx.doi.org/10.1037/0278-7393.18.6.1191

Smith, A. C., Monaghan, P., \& Huettig, F. (2017). The multimodal nature of spoken word processing in the visual world: Testing the predictions of alternative models of multimodal integration. Journal of Memory and Language, 93, 276-303. http://dx.doi.org/10.1016/j.jml.2016.08.005

Snodgrass, J. G., \& Vanderwart, M. (1980). A standardized set of 260 pictures: Norms for name agreement, image agreement, familiarity, and visual complexity. Journal of Experimental Psychology: Human Learning and Memory, 6, 174-215. http://dx.doi.org/10.1037/0278-7393.6.2.174

Staub, A., \& Clifton, C., Jr. (2006). Syntactic prediction in language comprehension: Evidence from either . . . or. Journal of Experimental Psychology: Learning, Memory, and Cognition, 32, 425-436. http://dx .doi.org/10.1037/0278-7393.32.2.425

Taylor, W. L. (1953). Cloze procedure: A new tool for measuring readability. Journalism Quarterly, 30, 415.

Van Berkum, J. J. A., Brown, C. M., Zwitserlood, P., Kooijman, V., \& Hagoort, P. (2005). Anticipating upcoming words in discourse: Evidence from ERPs and reading times. Journal of Experimental Psychology: Learning, Memory, and Cognition, 31, 443-467. http://dx.doi.org/10 1037/0278-7393.31.3.443

Van der Elst, W., Van Boxtel, M. P. J., Van Breukelen, G. J. P., \& Jolles, J. (2006). Normative data for the Animal, Profession and Letter M Naming verbal fluency tests for Dutch speaking participants and the effects of age, education, and sex. Journal of the International Neuropsychological Society, 12, 80-89. http://dx.doi.org/10.1017/ S1355617706060115

van Heuven, W. J. B., Mandera, P., Keuleers, E., \& Brysbaert, M. (2014). SUBTLEX-UK: A new and improved word frequency database for British English. Quarterly Journal of Experimental Psychology: Human Experimental Psychology, 67, 1176-1190. http://dx.doi.org/10.1080/ 17470218.2013.850521

Wicha, N. Y. Y., Moreno, E. M., \& Kutas, M. (2003). Expecting gender: An event related brain potential study on the role of grammatical gender in comprehending a line drawing within a written sentence in Spanish Cortex, 39, 483-508. http://dx.doi.org/10.1016/S0010-9452(08)70260-0

Wicha, N. Y. Y., Moreno, E. M., \& Kutas, M. (2004). Anticipating words and their gender: An event-related brain potential study of semantic integration, gender expectancy, and gender agreement in Spanish sentence reading. Journal of Cognitive Neuroscience, 16, 1272-1288. http:// dx.doi.org/10.1162/0898929041920487

Wlotko, E. W., \& Federmeier, K. D. (2013). Two sides of meaning: The scalp-recorded n400 reflects distinct contributions from the cerebral hemispheres. Frontiers in Psychology, 4, 181. http://dx.doi.org/10.3389/ fpsyg.2013.00181

Wolpert, D. M., Doya, K., \& Kawato, M. (2003). A unifying computational framework for motor control and social interaction. Philosophical Transactions of the Royal Society of London Series B, Biological Sciences, 358, 593-602. http://dx.doi.org/10.1098/rstb .2002 .1238

Yee, E., \& Sedivy, J. C. (2006). Eye movements to pictures reveal transient semantic activation during spoken word recognition. Journal of Experimental Psychology: Learning, Memory, and Cognition, 32, 1-14. http:// dx.doi.org/10.1037/0278-7393.32.1.1 


\section{Appendix}

\section{Stimulus Material}

\begin{tabular}{|c|c|c|c|c|c|c|c|}
\hline Target object & Predictable verb & Nonpredictable verb & Distractor 1 & Distractor 2 & Distractor 3 & $\begin{array}{c}\text { General } \\
\text { associations }\end{array}$ & $\begin{array}{l}\text { Functional } \\
\text { associations }\end{array}$ \\
\hline appel (apple) & schillen (peel) & tekenen (draw) & uil (owl) & kaars (candle) & radio (radio) & .58 & .82 \\
\hline baard (beard) & scheren (trim) & zien (see) & mand (basket) & typemachine (typewriter) & kurkentrekker (corkscrew) & .32 & .99 \\
\hline bal (ball) & trappen (kick) & lenen (borrow) & pak (suit) & krant (newspaper) & gitaar (guitar) & .11 & .49 \\
\hline band (tube) & verwisselen (change) & verliezen (loose) & ananas (pineapple) & colbert (jacket) & voet (foot) & .09 & .41 \\
\hline bank (coach) & bekleden (stiffen) & kiezen (choose) & worst (sausage) & pijp (pipe) & trommel (drum) & .4 & .7 \\
\hline beker (cup) & winnen (win) & bekijken (look at) & fontijn (fountain) & lieveheersbeestje (ladybug) & stoplicht (stoplight) & .15 & .78 \\
\hline biertje (beer) & drinken (drink) & kopen (buy) & handdoek (towel) & klok (clock) & potlood (pencil) & .24 & 1 \\
\hline bloem (flower) & planten (plant) & ontvangen (receive) & lucifer (match) & $\mathrm{CD}(\mathrm{CD})$ & koffer (suitcase) & .28 & .94 \\
\hline boek (book) & publiceren (publish) & verstoppen (hide) & spuit (injectionneedle) & plug (plug) & kom (bowl) & .32 & .91 \\
\hline boom (tree) & kappen (chop) & beschrijven (describe) & zebra (zebra) & vliegtuig (plane) & schoen (shoe) & .35 & .91 \\
\hline boterham (sandwich) & smeren (prepare) & betalen (pay) & pistool (pistol) & jurk (dress) & rugbybal (rugby-ball) & .15 & .68 \\
\hline broek (pants) & passen (fit) & zoeken (search) & zwaard (sword) & kikker (frog) & accordeon (accordion) & .1 & .67 \\
\hline cadeau (present) & krijgen (receive) & stelen (steal) & bh (bra) & paddestoel (mushroom) & aap (monkey) & .53 & .53 \\
\hline contract (contract) & ondertekenen (sign) & ontvangen (receive) & wijn (wine) & ballon (balloon) & hoed (hat) & .35 & .7 \\
\hline deur (door) & openen (open) & zoeken (search) & trui (sweater) & stethoscoop (stethoscope) & ontstopper (plunger) & .4 & .79 \\
\hline dief (thief) & arresteren (arrest) & filmen (film) & zeilboot (sailboat) & ijs-beer (ice-bear) & kasteel (castle) & .38 & .93 \\
\hline doos (box) & tillen (lift) & verbergen (hide) & theezakje (tea-bag) & magneet (magnet) & frisbee (frisbee) & .26 & .21 \\
\hline fiets (bike) & repareren (repair) & pakken (grab) & lippenstift (lipstick) & poes (cat) & ei (egg) & .42 & .71 \\
\hline glas (glass) & breken (break) & lenen (borrow) & telefoon (telephone) & schaar (scissors) & naaimachine (sewing-machine) & .48 & .33 \\
\hline hond (dog) & aaien (pet) & tekenen (draw) & schelp (shell) & vlag (flag) & robot (robot) & .27 & .7 \\
\hline huis (house) & bezitten (own) & kiezen (choose) & muffin (muffin) & dokter (doctor) & olifant (elephant) & .26 & .35 \\
\hline ijsje (ice-cream) & likken (lick) & overhandigen (hand over) & muts (cap) & zaag (saw) & bril (glasses) & .18 & .9 \\
\hline kind (child) & beschermen (protect) & beschrijven (describe) & wasknijper (clothespin) & veer (feather) & boter (butter) & .24 & .85 \\
\hline lamp (lamp) & vervangen (replace) & verbergen (hide) & borst (chest) & tak (branch) & wereldbol (globe) & .32 & .62 \\
\hline muur (wall) & behangen (decorate) & bewaken (guard) & draaimolen (carousel) & laptop (laptop) & schip (ship) & .48 & .7 \\
\hline overhemd (shirt) & strijken (iron) & zien (see) & aardappel (potato) & luidspreker (loudspeaker) & schop (shovel) & .1 & .94 \\
\hline piano (piano) & stemmen (tune) & stelen (steal) & bezem (broom) & kaas (cheese) & sjaal (scarf) & .08 & .93 \\
\hline pizza (pizza) & bestellen (order) & verkopen (sell) & harp (harp) & beksleutel (wrench) & skateboard (skateboard) & .1 & .22 \\
\hline sigaar (cigar) & roken (smoke) & verstoppen (hide) & hanger (hanger) & mok (mug) & boor (drill) & .16 & .66 \\
\hline sinaasappel (orange) & persen (squeeze) & overhandigen (hand over) & zaklamp (flashlight) & emmer (bucket) & bel (bell) & .33 & .92 \\
\hline standbeeld (statue) & onthullen (reveal) & bewaken (guard) & balkon (balcony) & slang (snake) & weg (road) & .27 & .48 \\
\hline stoel (chair) & verplaatsen (displace) & pakken (grab) & konijn (rabbit) & pijl (arrow) & brood (bread) & .15 & .23 \\
\hline taart (cake) & bakken (bake) & verkopen (sell) & fluit (flute) & spiegel (mirror) & bijl (ax) & .38 & .9 \\
\hline tafel (table) & dekken (prepare) & betalen (pay) & rugzak (backpack) & viool (violin) & fietspomp (bicycle-pump) & .51 & .87 \\
\hline $\operatorname{tas}(\mathrm{bag})$ & dragen (carry) & kopen (buy) & paard (horse) & fabriek (factory) & helikopter (helicopter) & .49 & .77 \\
\hline touw (rope) & spannen (take up) & verliezen (lose) & pen (pen) & kies (tooth) & slot (lock) & .44 & .84 \\
\hline trein (train) & missen (miss) & filmen (film) & haai (shark) & berg (mountain) & iglo (igloo) & .07 & .55 \\
\hline varken (pig) & slachten (slaughter) & fotograferen (take a photo) & bus (bus) & tent (tent) & sleutel (key) & .4 & .95 \\
\hline vis (fish) & vangen (catch) & fotograferen (take a photo) & waterkoker (kettle) & sneeuwpop (snowman) & palmboom (palm-tree) & .24 & .82 \\
\hline wond (wound) & hechten (suture) & bekijken (look at) & trompet (trumpet) & vogel (bird) & pan (pan) & .58 & .65 \\
\hline
\end{tabular}

Received March 15, 2016

Revision received December 1, 2016 Accepted December 17, 2016 